\title{
Myc supercompetitor cells exploit the NMDA receptor to subdue their wild-type neighbours via cell competition
}

Agnes R. Banreti1, ${ }^{1, *}$ and Pascal Meier ${ }^{1,2, *}$

1) The Breast Cancer Now Toby Robins Research Centre, The Institute of Cancer Research, London,

UK

2) Lead contact

* Correspondence:

pmeier@icr.ac.uk

abanreti@gmail.com

Tel: +44 (0)2071535326

Fax: +44 (0)20 71535340

Key words: NMDAR, competitiveness, cell competition, cell death, fitness, JNK-signalling, Myc, Ras

Running title: Myc and RasV12 cells require NR2 to be supercompetitors 
Banreti and Meier

\section{SUMMARY}

Myc is a major driver of cell growth in many cancers, but direct inhibition of Myc's oncogenic activity has been challenging. Interactions between wild-type and Myc-expressing cells cause Myc cells to acquire 'supercompetitor' behaviour that increases their fitness and enables them to overtake the tissue by killing their wild-type neighbours through TNF-induced cell death during a process called cell competition. Here we report that the competitive behaviour of Myc, RasV12 cells, and normal epithelial cells, critically depends on the NMDA receptor. Myc cells upregulate NMDAR2 (NR2) to gain supercompetitor status and subdue their wild-type neighbours. Pharmacological inhibition or genetic depletion of NR2 changes the supercompetitor status of oncogenic Myc or RasV12 clones into 'superlosers', resulting in their elimination via cell competition by wild-type neighbours in a TNF-dependent manner. Our data demonstrate that that the NMDA receptor (NMDAR) determines cellular fitness during cell competition, and can be targeted to change the fitness landscape of supercompetitive Myc and RasV12 clones, converting them into superlosers. 
Banreti and Meier

\section{Introduction}

Cell competition is an evolutionary conserved quality control process that eliminates suboptimal, but otherwise viable cells, thereby safeguarding tissue fitness and tissue homeostasis ${ }^{1}$. How relative fitness disparities are measured across groups of cells, and how the decision is taken whether a particular cell will persist in the tissue ('winner cell') or is killed ('loser cell') is not completely understood 2. This is an important issue as competitive behaviour is exploited by cells with deregulated oncogenes or tumour suppressors, which subsequently expand at the expense of, and with the help from, their cooperating wild-type (WT) neighbours ${ }^{1}$.

Growth signalling pathways involved in metabolic cell competition all seem to funnel through Myc, which functions as an essential signalling hub sustaining growth of many types of cancers. Myc regulates expression of components that control proliferation, cell death, differentiation, and central metabolic pathways. Particularly, acute changes in cellular metabolism appear to be critical for the winner phenotype during Myc supercompetition in Drosophila ${ }^{3}$.

Recent data demonstrate that living tumours can uptake lactate and preferentially utilize it over glucose to fuel TCA cycle and sustain tumour metabolism ${ }^{4}$. Moreover, the growth promoting effect of stromal cells is impaired by glycolytic inhibition, suggesting that the stroma provides nutritional support to malignant cells by transferring lactate from cancer-associated fibroblasts (CAFs) to cancer cells ${ }^{5,6}$. Such energy transfer from glycolytic stromal cells to epithelial cancer cells closely resembles physiological processes of metabolic cooperativity, such as in 'neuron-astrocyte metabolic coupling' in the brain, and the 'lactate shuttle' in the skeletal muscle ${ }^{7,8}$. Activation of glycolysis in astrocytes and MCT-mediated transfer of lactate to neurons supports neuron mitochondrial oxidative phosphorylation and energy demand ${ }^{9}$. These observations raise the intriguing possibility that lactate serves as fuel to complement glucose metabolism in both supercompetitors as well as tumours.

We report here that the NMDA receptor, a key component of the 'learning and memory' module, is repurposed to coordinate the competitiveness of epithelial cells within a tissue. We find that the activity of the NMDAR underpins cellular fitness in Drosophila epithelia during Myc- and RasV12-induced supercompetition, paradigms of cell competition with parallels to mammalian tumour promotion. 
bioRxiv preprint doi: https://doi.org/10.1101/2020.02.11.943498; this version posted February 12, 2020. The copyright holder for this preprint (which was not certified by peer review) is the author/funder. All rights reserved. No reuse allowed without permission.

\section{Banreti and Meier}

Inactivation of NMDAR changes the supercompetitor status of oncogenic Myc or RasV12 clones into 'superlosers', allowing their elimination by surrounding WT cells. Our data are consistent with the notion that NMDAR exerts its effect by regulating metabolic coupling between glycolytic loser and oxidative winner cells, driving loser cells to transfer their carbon fuel (lactate) to their neighbours. Preventing loser cells from 'donating' lactate to their neighbours removes fitness disparities and abrogates NMDARmediated cell competition. 
Banreti and Meier

\section{Results}

\section{Clonal depletion of NR2 results in the elimination of otherwise viable cells}

Genetic studies in Drosophila have revealed that tumour-driven cell competition eliminates nearby wildtype neighbours through TNF-dependent cell death, allowing the expansion of oncogene-induced supercompetitor clones ${ }^{1,3,10}$. However, the initial mechanism by which cells acquire supercompetitor status to drive cell competition has remained unknown. To identify components that sense fitness disparities during cell competition, we conducted a candidate-based approach in Drosophila using hetero- (GFP-marked loser clones among winners - genetic mosaic background) and homotypic (GFPmarked loser clones among losers) competition assays in the developing imaginal wing disc (Figure 1A). Comparison of clonal survival in hetero- versus homotypic genetic backgrounds allows the exclusion of genes that compromise cell viability in general. In Drosophila, oncogenic polarity-deficient mutant cells for Discs Large 1 (Dlg1) are eliminated by wild-type neighbours through cell competition 11. Dlg1 is the highly conserved homologue of mammalian PSD-95 and SAP97, which directly bind to the carboxy-terminal tail of NR2B ${ }^{12,13}$, a subunit of the $N$-methyl-D-aspartate receptor (NMDAR). NMDAR is best known for its involvement in neuronal activities, including the vast majority of excitatory neurotransmission in the brain, neuronal migration, synaptogenesis, neuronal plasticity, survival, excitotoxicity and lactate-mediated metabolic coupling between neurons and astrocytes ${ }^{14,15}$. Through these activities NMDA receptors (NMDARs) play roles in long-term memory consolidation, the development of drug addiction, pain perception, and the pathogenesis of neurological disorders ${ }^{15}$. While NMDARs are mainly present in neurons, recent studies indicate that NMDAR subunits are also expressed in non-neuronal tissues ${ }^{16,17}$. Moreover, high expression of NMDAR is present in various types of cancers, such as human neuroblastoma, breast cancer, small-cell lung cancer and ovarian cancer $18,19,20,21$. Although NMDARs have been extensively studied in the brain, their role in nonneuronal tissues or cancer cells is poorly defined. While there are seven different NMDAR subunits in mammals, Drosophila encodes only two NMDAR subunits (NR1 and NR2), which simplifies their study. Our analyses using anti-NR2 antibody staining (Figure S1A) and translational reporter of NR2 $(N R 2:: G F P)$ (Figure S1B), confirmed that NR2 is not only expressed in the Drosophila central nervous system ${ }^{22,23}$ but also in a wide range of developing tissues such as imaginal eye-, and wing discs as well as salivary gland and fat body (Figure S1A-S1C), which is consistent with previously published RNAseq data ${ }^{17}$. 
Banreti and Meier

To study the role of NR2 in cell competition in wing discs, we generated mosaic tissues of two clonal populations. This confronts wild-type cells (WT) with clones of cells in which the gene-of-interest (goi) is depleted by RNAi (Figure 1A, left panel). Such RNAi clones were marked with green fluorescent protein (GFP). Interestingly, clonal knockdown of NR2 (subsequently referred to as NR2 clones) using five different RNAi constructs (Figures 1B and 1D) resulted in the elimination of the NR2 clones (Figures $1 \mathrm{C}$ and 1D). Likewise, and as previously demonstrated ${ }^{24,25}$, clonal knockdown of Dlg1 or Scribble (Scrib) (losers among winners) resulted in the elimination of 'loser' knockdown-clones (Figure 1D and Figure S2A). In contrast, clonal depletion of LacZ, which served as RNAi control, had no effect (Figures 1C and 1D), Importantly, RNAi-mediated depletion of NR2 or Dlg1 had no effect on clonal survival under homotypic condition (losers among losers), such as upon tissue-wide NR2 depletion using nubbin-Gal4 (Figures 1E and 1F, Figure S2B) or hedgehog (hh)-Gal4 (Figure S2C) that drive expression of the RNAi constructs in the entire wing pouch or posterior compartment of the Drosophila wing imaginal disc, respectively. The observation that NR2-depleted cells are lost from the tissue when surrounded by WT cells, but are fully viable under homotypic conditions, demonstrates that clonal reduction of NR2 triggers competitive interactions, resulting in the elimination of otherwise viable cells.

Homotypic clonal analysis demonstrated that the growth rate of NR2 clones is equivalent to the one of control LacZ cells (Figure 1G), highlighting that NR2 depletion does not impair cell viability or growth in general. Further, treatment with AP5 ((2R)-amino-5-phosphonopentanoate), a selective inhibitor of NR2 ${ }^{26}$, suppressed the elimination of NR2 clones in a heterotypic genetic background (losers among winners) (Figures $1 \mathrm{H}$ and $1 \mathrm{l}$ ), phenocopying a homotypic setting. This illustrates that the competitive behaviour between NR2-losers and WT-winners is due to a relative difference in NR2 activity among competing clones. AP5-medited global inhibition of NR2 thereby seems to eradicate the "fitness disparity" among competing clones. Together, out data demonstrate that depletion of NR2 does not inherently compromise cell viability. However, when surrounded by WT cells, NR2-depleted cells are recognized and actively eliminated.

Elimination of NR2 loser clones via apoptosis is dependent on the TNF>JNK-signalling axis 
Banreti and Meier

To study the elimination process of NR2-depleted cells, we examined the possible involvement of the Grindelwald $>$ JNK signalling axis ${ }^{27}$. While NR2-depleted cells were readily eliminated, such loser clones survived upon simultaneous clonal depletion of the Drosophila TNF-receptor superfamily member Grindelwald (Grnd) (Grnd-RNAi), hemipterous (hep) (hep-RNAi) or inactivation of basket (bsk) (UASbsk-dominant negative $(D N))$, demonstrating that NR2 clones are eliminated in a Grnd- and JNKdependent manner (Figure 2A). Consistent with an involvement of JNK signalling, we found intense staining of activated JNK [p-JNK] (Figure 2B), induction of the JNK activity reporter PucLacZ (Figure $\mathrm{S} 3 \mathrm{~A}$ ) and high expression level of the JNK target gene MMP1 (JNK target) in and around NR2 clones (Figure 2C). JNK signalling in NR2 clones ultimately resulted in caspase-mediated cell death because expression of the caspase inhibitors p35 and DIAP1 suppressed the elimination of NR2 clones (Figure 2A). Consistently, we observed cells positive for cleaved caspase staining with anti-cleavedDCP1 (anticDCP1) (Figure S3B).

JNK-mediated inactivation of PDH in loser cells induces aerobic glycolysis and lactate production

JNK signalling can lead to activation of the mitochondrial Pyruvate Dehydrogenase Kinase (PDK), which in turn can phosphorylate and inactivate Pyruvate Dehydrogenase (PDH), a key enzyme that catalyses the oxidative decarboxylation of pyruvate to produce acetyl coenzyme $\mathrm{A}, \mathrm{NADH}$ and $\mathrm{CO}_{2}{ }^{28}$. Phospho-dependent inactivation of PDH decreases mitochondrial activity and enhances the conversion of pyruvate to lactate in the cytosol ${ }^{29}$. To test whether depletion of NR2 results in metabolic reprogramming, we monitored the phosphorylation status of $\mathrm{PDH}$. As shown in Figure 3A and Figures S4A- S4C, we detected prominent phospho-PDH (p-PDH) staining in NR2-RNAi loser clones. Enhanced p-PDH staining was strictly JNK-dependent as inhibition of JNK signalling abrogated p-PDH staining (Figure 3A). Consistent with PDH inactivation in NR2-RNA clones, we noticed a decreased average size of mitochondria (Figure S4D)).

Next, we tested the importance of PDK and p-PDH for the elimination of NR2-RNAi loser clones. Intriguingly, co-depletion of PDK completely rescued the elimination of NR2-loser clones (Figures 3B and $3 \mathrm{C}$ ) and abrogated the appearance of cleaved DCP1 positive cells (Figure S4E). Likewise, Gal4driven expression of PDH in NR2-loser clones blocked their elimination (Figures 3B and 3C). In both 
Banreti and Meier

settings, surviving NR2-clones were negative for anti-p-PDH staining (Figure 3B). Together, these data indicate that PDK-mediated phosphorylation and inactivation of PHD is required for the death of NR2loser clones.

\section{Loser cells die by 'donating' their lactate to winners}

Since inactivation of $\mathrm{PDH}$ results in aerobic glycolysis, we assessed whether metabolic reprogramming of loser cells might contribute to their elimination. During aerobic glycolysis, most glucose carbon is converted to pyruvate via glycolysis and reduced to lactate via lactate dehydrogenase $(\mathrm{LDH})^{30}$, which is then secreted. While lactate exits cells via monocarboxylate transporter (e.g. MCT1) to avoid acidification, it can be recaptured and used as source of energy by neighbouring cells, leading to metabolic compartmentalisation between adjacent cells ${ }^{4,}{ }^{31}$. To test the involvement of lactate exchange from losers to winners during cell competition, we exposed flies to food containing lactate (Llactic acid, LLA). We hypothesised that lactate feeding might flatten a putative lactate gradient between losers and winners and hence block cell competition. Intriguingly, lactate feeding blocked the elimination of NR2-loser clones (Figures 4A and 4B). Consistent with the notion that lactate transport from NR2losers to winners is important for loser/winner relationships and cell competition, we found that blocking loser cells to produce and transport lactate to winner cells rescued loser cell elimination. Accordingly, concomitant down-regulation of the lactate dehydrogenase ImpL3 in NR2 loser clones, like coknockdown of the lactate transporter monocarboxylate transporter 1 (Mct1), completely rescued NR2 clone elimination (Figures $4 \mathrm{~A}$ and $4 \mathrm{~B}$ ). This effect was specific to MCT1, as silencing the putative monocarboxylate transporters CG13907 or CG3409 within loser clones had no effect on NR2-loser cell elimination (Figure 4B). Pharmacological inhibition of MCT1 also blocked cell competition and the elimination of NR2 loser clones (Figures 4A and 4B). Consistent with these results, we observed elevated levels of MCT1 in NR2-RNAi cells (Figure S5). Together, these data suggest that preventing loser cells from transferring lactate to their neighbours may remove fitness disparities and inhibit cell competition.

NR2 is essential for the supercompetitior status of Myc- and RasV12-expressing cells In mosaic wing imaginal discs, interactions between WT and Myc- or RasV12-expressing cells cause oncogene expressing cells to acquire 'supercompetitor' behaviour that increases their fitness and 
bioRxiv preprint doi: https://doi.org/10.1101/2020.02.11.943498; this version posted February 12, 2020. The copyright holder for this preprint (which was not certified by peer review) is the author/funder. All rights reserved. No reuse allowed without permission.

Banreti and Meier

enables them to overtake the tissue by killing their WT neighbours ${ }^{32,}{ }^{33}$. To test the potential role of NR2 for the suppercompetitor status of Myc-expressing cells, we first examined the levels of NR2 in Myc clones. As shown in Figures 5A and 5B Myc supercompetitor clones exhibited significantly higher levels of NR2 than surrounding wild-type neighbours, both in the wing disc as well as fat body. Moreover, such Myc supercompetitor clones also had higher levels of the ligand for NR2, Glutamate (Figure 5C).

To test whether NR2 contributes to the supercompetitor status of oncogenic Myc, we depleted NR2 in Myc supercompetitor clones. While clonal expression of oncogenic Myc on its own resulted in large hyperplastic clones, such Myc winners were eliminated when NR2 was simultaneously knocked down in these clones (Figures 6A and 6C). Likewise, clones expressing oncogenic Ras V12 were also eliminated when NR2 was depleted in RasV12 clones (Figures 6B and 6C). Further, we found that depletion of NR2 in RasV12 clones not only eliminated RasV12 clones but also rescued pupal lethality, which is associated with the neoplastic growth of Ras V12 clones and the development of Ras V12 tumours (Figure 6D). Together, these data demonstrate that the supercompetitor status of Myc, and the potential of RasV12 cells to form tumours, critically depends on the presence of NR2. Importantly, Mycand RasV12-expressing NR2 clones were eliminated only in heterotypic settings, when surrounded by WT cells. Accordingly, tissue-wide (nub-Gal4) expression of Myc;NR2-RNAi or RasV12;NR2-RNAi did not lead to the elimination of GFP+ pseudo-clones, demonstrating that such Myc;NR2-RNAi and RasV12/NR2-RNAi clones are intrinsically viable (Figure 6E), but when surrounded by WT cells are eliminated via cell competition and caspase-mediated cell death (Figure 6F).

Next, we monitored the p-PDH (metabolic reprogramming) status in WT and Myc or RasV12 supercompetitor cells to assess whether lactate-mediated metabolic coupling might be important for loser/supercompetitor relationships. Under homotypic conditions, no p-PDH staining was apparent in WT cells (Figure S6A and Figure S7 top panel). However, prominent p-PDH staining was detectable in WT cells that were juxtaposed to Myc or RasV12 winner clones (Figures S6B-S6D and Figure S7 middle panel). Interestingly, depletion of NR2 in RasV12 clones, which renders them losers, lead to strong pPDH staining in such clones (Figure S7, bottom panel). This suggests that depletion of NR2 reprograms metabolism via phosphorylation-dependent inactivation of PDH and consequential shut down of 
Banreti and Meier

pyruvate catalysis, leading to enhanced production and disposal of lactate. According to our model (Figure 4A), this then results in the transfer of lactate from losers to their neighbours, providing them with winner status. Hence, altered metabolism of loser cells may be due to lower NR2 activity. Together, our data suggest that NR2-mediated regulation of metabolism may influences cell competition.

\section{Discussion}

The active elimination of unfit cells via competitive interactions plays an important role for the maintenance of tissue health during development and adulthood ${ }^{1,2,34,35,36}$. Our data indicate that the activity of NR2 influences the competitive behaviour of epithelia cells and Myc or RasV12 supercompetitors. We find that pharmacological inhibition or genetic depletion of NR2 reprograms metabolism via TNF-dependent and JNK-mediated activation of PDK, which in turn phosphorylates and inactivates PDH. This causes a shutdown of pyruvate catalysis and results in a switch to aerobic glycolysis. In the absence of functional PDH, pyruvate is reduced to lactate via LDH, and secreted ${ }^{30}$. Disposal of this large carbon pool as lactate serves multiple functions. While lactate exits cells to avoid acidification, it can be recaptured and used as carbon source by other cells, leading to metabolic compartmentalisation between adjacent cells. In normal physiology as well as in murine and human tumours, lactate is an important energy source that fuels mitochondrial metabolism ${ }^{4,31}$. For example, lactate produced and secreted by astrocytes is transported to neighbouring neurons where it is used as source of energy to support neuronal function ${ }^{14}$. This is akin of the 'reverse Warburg effect' ${ }^{6}$, also named 'two-compartment metabolic coupling' model, where cancer-associated fibroblasts (CAFs) undergo aerobic glycolysis and production of high energy metabolites, especially lactate, which is then transported to adjacent cancer cells to sustain their anabolic need ${ }^{6}$.

Our data suggest that epithelial NMDA receptor activity is responsible for fitness surveillance and to provide clones with oncogenic mutations supercompetitor status. Cells with decreased epithelial NMDA receptor activity become classified as 'less fit' and are metabolically reprogrammed to donate their carbon fuel to their neighbours, rendering them 'fitter'. According to our model, differential NMDAR signalling in adjacent cells triggers lactate-mediated metabolic coupling, and underpins cell competition in epithelia. Consistently, preventing loser cells from 'donating' lactate to their neighbours removes the fitness disparity and nullifies cell competition. Likewise, exposure to elevated levels of systemic lactate, 
Banreti and Meier

such as upon lactate feeding, completely blocks elimination of NR2 loser clones, most likely because excessive lactate exposure 'flattens' the fitness disparity. This suggests that cell competition may be based on NMDAR-mediated metabolic coupling between winners and losers. Importantly, this metabolic coupling only occurs if adjacent cells have differential NMDAR signalling. Consistently, NR2 losers are only eliminated if they are surrounded by cells with functional NMDAR. This is evident as tissue-wide inhibition of NMDAR by AP5, a selective inhibitor of NR2, blocks elimination of NR2 loser clones in a heterotypic genetic setting.

Like in flies, NMDAR also seems to be upregulated in genetically engineered mouse models of cancer, where it induces an autocrine glutamate signalling circuit with resultant stimulation of malignancy ${ }^{21}$. Furthermore, the NMDAR pathway is evident in various human tumours and cell lines, and its expression level is associated with poor cancer patient prognosis ${ }^{21}$. We find that NR2 is upregulated in Myc expressing clones and that such cells co-opt epithelial NR2 to promote cell competition, subduing their neighbouring wild-type cells that become re-classified as 'unfit'. Given that Myc is a major driver of cancer cell growth, and is a hallmark of the disease in nearly seven out of ten cases, blocking Myc's function would be a powerful approach to treat many types of cancer. However, the properties of the Myc protein itself make it difficult to design a drug against it. We now find that inactivating NR2 in Myc or RasV12 clones kills these cells in a strictly cell competition-dependent manner.

Together, our data suggest that Myc and RasV12 clones critically depend on the activity of NR2 for their supercompetitor status, and that NR2 could serve as an attractive therapeutic target against various types of cancers that have deregulated levels of NR2, with no apparent effects on homotypic wild-type neighbours. This highlights new vulnerabilities of clones with oncogenic mutations, and may pave the way for new anti-cancer treatment approaches that are based on cell competition. 
bioRxiv preprint doi: https://doi.org/10.1101/2020.02.11.943498; this version posted February 12, 2020. The copyright holder for this preprint (which was not certified by peer review) is the author/funder. All rights reserved. No reuse allowed without permission.

Banreti and Meier

\section{References}

1. Johnston LA. Socializing with MYC: cell competition in development and as a model for premalignant cancer. Cold Spring Harbor perspectives in medicine 4, a014274 (2014).

2. Claveria C, Torres M. Cell Competition: Mechanisms and Physiological Roles. Annu Rev Cell Dev Biol 32, 411-439 (2016).

3. de la Cova C, et al. Supercompetitor status of Drosophila Myc cells requires p53 as a fitness sensor to reprogram metabolism and promote viability. Cell metabolism 19, 470-483 (2014).

4. Faubert B, et al. Lactate Metabolism in Human Lung Tumors. Cell 171, 358-371 e359 (2017).

5. Bonuccelli G, et al. Ketones and lactate "fuel" tumor growth and metastasis: Evidence that epithelial cancer cells use oxidative mitochondrial metabolism. Cell Cycle 9, 3506-3514 (2010).

6. Pavlides S, et al. The reverse Warburg effect: aerobic glycolysis in cancer associated fibroblasts and the tumor stroma. Cell Cycle 8, 3984-4001 (2009).

7. Nedergaard M, Goldman SA. Carrier-mediated transport of lactic acid in cultured neurons and astrocytes. Am J Physiol 265, R282-289 (1993).

8. Brooks GA. Lactate production under fully aerobic conditions: the lactate shuttle during rest and exercise. Fed Proc 45, 2924-2929 (1986).

9. Brooks GA, Dubouchaud H, Brown M, Sicurello JP, Butz CE. Role of mitochondrial lactate dehydrogenase and lactate oxidation in the intracellular lactate shuttle. Proc Natl Acad Sci U S A 96, 1129-1134 (1999).

10. Meyer SN, et al. An ancient defense system eliminates unfit cells from developing tissues during cell competition. Science, in press (2014).

11. Bilder D. Epithelial polarity and proliferation control: links from the Drosophila neoplastic tumor suppressors. Genes Dev 18, 1909-1925 (2004).

12. Kornau HC, Schenker LT, Kennedy MB, Seeburg PH. Domain interaction between NMDA receptor subunits and the postsynaptic density protein PSD-95. Science 269, 1737-1740 (1995).

13. Niethammer M, Kim E, Sheng M. Interaction between the C terminus of NMDA receptor subunits and multiple members of the PSD-95 family of membrane-associated guanylate kinases. J Neurosci 16, 2157-2163 (1996).

14. Steinman MQ, Gao V, Alberini CM. The Role of Lactate-Mediated Metabolic Coupling between Astrocytes and Neurons in Long-Term Memory Formation. Frontiers in integrative neuroscience 10, 10 (2016).

15. Paoletti P, Bellone C, Zhou Q. NMDA receptor subunit diversity: impact on receptor properties, synaptic plasticity and disease. Nat Rev Neurosci 14, 383-400 (2013).

16. Hogan-Cann AD, Anderson CM. Physiological Roles of Non-Neuronal NMDA Receptors. Trends Pharmacol Sci 37, 750-767 (2016).

17. Potier D, et al. Mapping gene regulatory networks in Drosophila eye development by largescale transcriptome perturbations and motif inference. Cell reports 9, 2290-2303 (2014).

18. North WG, Gao G, Jensen A, Memoli VA, Du J. NMDA receptors are expressed by small-cell lung cancer and are potential targets for effective treatment. Clinical pharmacology : advances and applications 2, 31-40 (2010). 
bioRxiv preprint doi: https://doi.org/10.1101/2020.02.11.943498; this version posted February 12, 2020. The copyright holder for this preprint (which was not certified by peer review) is the author/funder. All rights reserved. No reuse allowed without permission.

Banreti and Meier

19. North WG, Gao G, Memoli VA, Pang RH, Lynch L. Breast cancer expresses functional NMDA receptors. Breast Cancer Res Treat 122, 307-314 (2010).

20. North WG, Liu F, Tian R, Abbasi H, Akerman B. NMDA receptors are expressed in human ovarian cancer tissues and human ovarian cancer cell lines. Clinical pharmacology : advances and applications 7, 111-117 (2015).

21. Li L, Hanahan D. Hijacking the neuronal NMDAR signaling circuit to promote tumor growth and invasion. Cell 153, 86-100 (2013).

22. Wu CL, et al. Specific requirement of NMDA receptors for long-term memory consolidation in Drosophila ellipsoid body. Nat Neurosci 10, 1578-1586 (2007).

23. Xia S, et al. NMDA receptors mediate olfactory learning and memory in Drosophila. Curr Biol 15, 603-615 (2005).

24. Brumby AM, Richardson HE. scribble mutants cooperate with oncogenic Ras or Notch to cause neoplastic overgrowth in Drosophila. Embo J 22, 5769-5779 (2003).

25. Igaki T, Pagliarini RA, Xu T. Loss of cell polarity drives tumor growth and invasion through JNK activation in Drosophila. Curr Biol 16, 1139-1146 (2006).

26. Olverman HJ, Jones AW, Watkins JC. L-glutamate has higher affinity than other amino acids for [3H]-D-AP5 binding sites in rat brain membranes. Nature 307, 460-462 (1984).

27. Andersen DS, et al. The Drosophila TNF receptor Grindelwald couples loss of cell polarity and neoplastic growth. Nature 522, 482-486 (2015).

28. Zhou Q, Lam PY, Han D, Cadenas E. Activation of c-Jun-N-terminal kinase and decline of mitochondrial pyruvate dehydrogenase activity during brain aging. FEBS Lett 583, 1132-1140 (2009).

29. Linn TC, Pettit FH, Reed LJ. Alpha-keto acid dehydrogenase complexes. X. Regulation of the activity of the pyruvate dehydrogenase complex from beef kidney mitochondria by phosphorylation and dephosphorylation. Proc Natl Acad Sci U S A 62, 234-241 (1969).

30. Rogatzki MJ, Ferguson BS, Goodwin ML, Gladden LB. Lactate is always the end product of glycolysis. Frontiers in neuroscience 9, 22 (2015).

31. Hui S, et al. Glucose feeds the TCA cycle via circulating lactate. Nature 551, 115-118 (2017).

32. Moreno E, Basler K. dMyc transforms cells into super-competitors. Cell 117, 117-129 (2004).

33. de la Cova $C$, Abril M, Bellosta $P$, Gallant $P$, Johnston LA. Drosophila myc regulates organ size by inducing cell competition. Cell 117, 107-116 (2004).

34. Amoyel M, Bach EA. Cell competition: how to eliminate your neighbours. Development 141, 988-1000 (2014).

35. Di Gregorio A, Bowling S, Rodriguez TA. Cell Competition and Its Role in the Regulation of Cell Fitness from Development to Cancer. Dev Cell 38, 621-634 (2016).

36. Baker NE. Mechanisms of cell competition emerging from Drosophila studies. Curr Opin Cell Biol 48, 40-46 (2017).

37. Kashio S, Obata F, Zhang L, Katsuyama T, Chihara T, Miura M. Tissue nonautonomous effects of fat body methionine metabolism on imaginal disc repair in Drosophila. Proc Natl Acad Sci $U$ $S$ A 113, 1835-1840 (2016). 
Banreti and Meier

38. Chang YY, Neufeld TP. An Atg1/Atg13 complex with multiple roles in TOR-mediated autophagy regulation. Mol Biol Cell 20, 2004-2014 (2009).

\section{Acknowledgments}

We would like to thank Laura Johnston, Ann-Shyn Chiang, M. Miura for reagents, and Rebecca Wilson, Sidonie Wicky John, Tencho Tenev, Marta Fores Maresma, Celia Domingues, and Katalin Schlett for technical assistance. We would like to thank Bruno Hudry and members of the Meier laboratory for discussions and critical reading of the ms. We would like to apologize to the many authors whose work we could not cite due to space restrictions. A.B. was funded by an EMBO Long Term Fellowship (ALTF48-2014). Work in the Meier lab is funded by Breast Cancer Now (CTR-QR14-007) and Biological Sciences Research (BBSRC) (BB/L021684/1). We acknowledge NHS funding to the NIHR Biomedical Research Centre.

\section{Author Contributions}

A.B. conceived the study, A.B. and P.M designed the experiments, and A.B. performed the experiments. A.B. and P.M. analysed the data and wrote the manuscript.

Author Information The authors declare no competing financial interests. Readers are welcome to comment on the online version of the paper. Correspondence and requests for materials should be addressed to P.M. (pmeier@icr.ac.uk). 
Banreti and Meier

\section{METHODS}

Fly strains. The following strains were used: UAS-LacZ-RNAi ${ }^{37}$ (from M. Miura), UAS-dlg1 GD41136 RNAi Nienna Drosophila Resource Center, VDRC), UAS-NR2 ${ }^{T W}-R N A i^{22}$ (from A.S. Chiang), UAS-

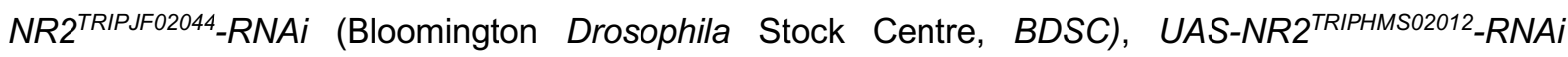

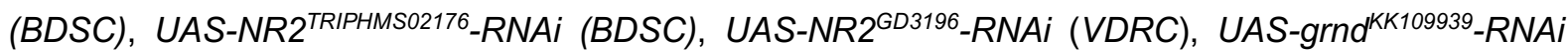
(VDRC), UAS-pvf1-RNA; ${ }^{39038}$ (BDSC); UAS-hep ${ }^{G D 26929-R N A i ~(V D R C), ~ U A S-b s k-D N ~(B D S C ~ 6409), ~}$ UAS-p35,UAS-DIAP1 (PMID: 10675329), pucE69(puc-LacZ) (from P. Ribeiro), UAS-CaMKII T287D

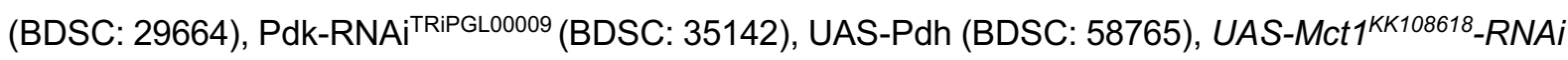

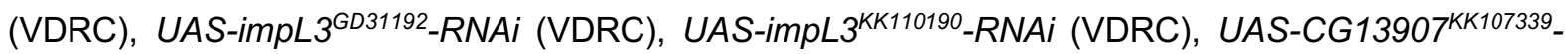

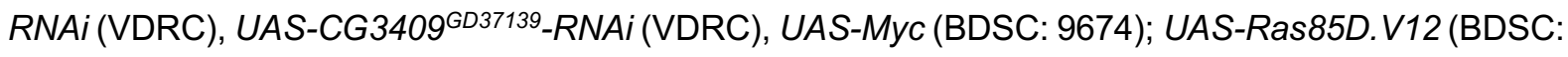
64196), nub-Gal4 (BDSC: 25754), hh-Gal4 (BDSC:45946 III), NR2[MI09281-GFSTF.2] (BDSC: 60566), UAS-GCaMP3 ${ }^{N L S}$ (from C. Schuster) (PMID: 23652205). For the generation of GFP-marked clones the following strains were used: $\mathrm{y}, \mathrm{w}, h s-f l p ; ; A c t<C D 2<G a l 4, U A S-n E G F P{ }^{38}$ (from T. Neufeld) and Ubip63E<FRT.STOP.FRT<Stringer(nEGFP) (BDSC: 32251).

Fly husbandry. Fly stocks were reared on a standard corn meal/agar diet (6.65 \% corn meal, $7.15 \%$ dextrose, $5 \%$ yeast, $0.66 \%$ agar, supplemented with $2.2 \%$ nipagin and $3.4 \mathrm{ml} / /$ propionic acid). All experimental flies were kept at $24^{\circ} \mathrm{C}$ on a 12 hours light/dark cycle. Flies crosses were set up and kept for 3 days at $24^{\circ} \mathrm{C}$. Flies were transferred to fresh vials every day, and fly density was kept to a maximum of 15 flies per vial. For clonal flip-out experiments (homotypic and heterotypic assays), flies were allowed to lay eggs in fresh tubes for 3 hours. 72 hours after egg laying (AEL) larvae were incubated at $37^{\circ} \mathrm{C}$ for 10 minutes to induce transgene expression. Following temperature shift, animals were kept at $24{ }^{\circ} \mathrm{C}$. Imaginal wing discs were dissected 48 hours after heat-shock-mediated induction of clones. For the experiment shown in Figure 3D, clones were induced as above. After clone induction, flies were raised for 10 days at $24{ }^{\circ} \mathrm{C}$. The numbers of eclosed imagoes and dead pupae were counted and the ratio of imago/total per vial was calculated.

Homotypic and heterotypic cell competition assays. Homotypic assay: hsFlp;nub-Gal4;ubip63<FRT.STOP.FRT<Stringer(nEGFP) flies were crossed to flies carrying the respective UAS-based transgenes. nub-Gal4 drives expression of the UAS-transgene in the entire wing pouch. Heat shock 
Banreti and Meier

generates nEGFP-positive 'pseudoclones', which have the same genotype as the surrounding wing pouch. Heterotypic assay: $h s F I p ; ; A c t<C D 2<G a / 4, U A S-n E G F P$ flies were crossed to flies carrying the respective UAS-based transgenes. Heat shock generates flip-out clones, removing the $<C D 2<$ cassette, which allows expression of the UAS-based transgenes. Such clones are marked by nEGFP expression.

Immunohistochemistry. Larval tissues were stained using standard immunohistochemical procedures. Briefly, discs were dissected in PBS, fixed at room temperature for 20 mins in $3.7 \%$ formaldehyde/PBS and washed in $2 \%$ Triton-X100/PBS. All subsequent incubations were performed in $2 \%$ Triton X-100/PBS at $4{ }^{\circ} \mathrm{C}$. Samples were mounted either in Vectashield or Vectashield containing DAPI (Vector Labs). The following primary antibodies were used: mouse anti-dNR222 (1:100, from AnnShyn Chiang), mouse anti-NR2B (1:200, Clone 13, Mouse 610416, BD Biosciences), mouse monoclonal anti-N2B (1:200, [S59-36], ARG22230, Arigobio/2BScientific Ltd.), mouse anti-Dlg (1:50, 4F3, DSHB, University of lowa, lowa City, IA, USA), mouse anti-GFP (11814460001, Roche), mouse anti-MMP1 (1:50, 5H7B11, DSHB, University of lowa, lowa City, IA, USA), rabbit anti-cleaved DCP1 (Asp216) Cell Signaling), rabbit p-JNK (1:100, Drosophila p-JNK (Thr183/Tyr185), 81E11, Cell Signaling Technology Inc., Danvers, MA, USA), PHA-555 (Phalloidin-555, A34055, Invitrogen/Molecular probes), mouse polyclonal Anti-MCT1 (ab90582, Abcam), rabbit polyclonal anti-pPDHE1 (Pyruvate Dehydrogenase E1-alpha subunit (phospho S293), ab92696, Abcam). Note, the phosphorylation site surrounding S296 of human PDHE1 is conserved in Drosophila PDHE1, which is encoded by lethal(1)G0334 (CG7010) (e-value 5e-36, query coverage of 99\%). Fluorescent secondary antibodies (FITC-, Cy3- and Cy5-conjugated) were obtained from Jackson Immunoresearch.

Lactate feeding and treatments with inhibitors. Following heat shock-mediated clone induction, larvae were placed on standard food containing L-lactate (30 mM, 71718-10G, Sigma Aldrich), the NR2

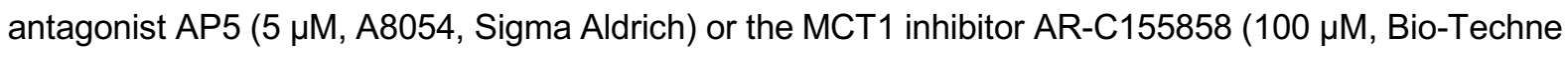
(Tocris)) for $48 \mathrm{hrs}$.

Quantifications. Imaginal discs were imaged at 20x magnification. Seven Z-stacks were taken for each disc. After imaging, channels were split and maximum Z-projection was analysed. Using DAPI channel 
Banreti and Meier

images, a line was drawn around the pouch area and measured using ImageJ. The sum areas of GFPpositive clones were measured using the GFP channel. Threshold was adjusted with the Huang autotresholding algorithm to subtract background. The area above the threshold was analysed. Data were collected from at least three independent experiments, and 10 wing discs per genotype and/or condition were analysed, unless stated otherwise. The relative occupancy of GFP positive clones was quantified, and expressed as proportion of GFP-positive clones per pouch ( \pm S.D.).

Statistics and data presentation. All statistical analyses were carried out using GraphPad Prism7. Comparisons between two genotypes/conditions were analysed with the Mann-Whitney nonparametric two-tailed rank U-test or Pearson's correlation test. Confocal images belonging to the same experiment, and displayed together, were acquired using the same settings. For the purpose of visualization, the same level and channel adjustments were applied using ImageJ. Of note, all quantitative analyses were carried out on unadjusted raw images or maximum projections. Values are presented as average \pm standard deviation (S.D.), $P$-values from Mann-Whitney U-test (non-significant (ns): $P>0.05$; *: $0.05>P>0.1 ;{ }^{* *}: 0.1>P>0.01 ;{ }^{* * *}: 0.01>P>0.001{ }^{* * * *}: P>0.0001$ and from Pearson's analysis $\alpha=0.05$. 
Banreti and Meier

\section{Figure Legends}

\section{Figure 1. Clonal depletion of $N R 2$ results in the elimination of otherwise viable cells.}

(A) Schematic representation of the genetic systems used to study cell competition in the Drosophila wing pouch. Left panel: Heterotypic genetic system with GFP marking loser clones. Right panel: homotypic genetic system with GFP marking pseudo-clones. (B) The $N$-methyl-D-aspartate receptor (NMDAR) is a hetero-tetrameric receptor consisting of two NR1 subunits and two NR2 subunits. Linear representation of the modular amino-terminal domain (ATD, green), ligand-binding domain (LBD, blue), transmembrane domains (yellow) and C-terminal domain (grey). Indicated are the names and position of the respective NR2-shRNAi constructs used in this study. (C) Heterotypic clonal analysis. The indicated genes-of-interest (goi) were knocked down in GFP-marked clones as depicted in a (left panel, see Methods for details). Loser clones are marked by GFP (green). Specific genotypes of the discs shown in these panels, and all subsequent panels, can be found in Extended Data Table. Scale bar $100 \mu \mathrm{m}$. (D) Quantification of the heterotypic competition assay. Diagram shows the average occupancy of the indicated RNAi clones per wing pouch. (E) Homotypic clonal analysis. The indicated genes-of-interest were knocked down throughout the wing pouch as described in a (right panel). GFPmarked clones represent pseudoclones. Scale bar $100 \mu \mathrm{m}$. (F) Quantification of the homotypic competition assay. Diagram shows the average occupancy of pseudoclones in the indicated wing pouches where the respective gene-of-interest were knocked down. (G) Relative rates of growth under hetero versus homotypic clonal settings. $(\mathbf{H})$ Heterotypic clonal analysis in the presence or absence AP5, an inhibitor of NR2. Scale bar $100 \mu \mathrm{m}$. (I) Quantification of the AP5 treatment assay. Error bars represent average occupancy of the indicated RNAi clones per wing pouch \pm SD. ${ }^{* * * *} P<0.0001$, ${ }^{* * *} P<0.001,{ }^{* *} P<0.01,{ }^{*} P<0.1$ by Mann-Whitney nonparametric $U$-test. $n$ depicts the number of wing discs. See Supplemental Information Table for genotypes.

\section{Figure 2. NR2 loser clones are eliminated by apoptosis via the TNF $>$ JNK signalling axis.}

(A) Heterotypic clonal analysis. Schematic representation of the TNF>JNK signalling pathway. The indicated genes-of-interest (goi) were knocked down or misexpressed (UAS-bsk-DN, UAS-p35,Diap1) in GFP-marked clones as depicted in Figure 1aA (left panel). Loser clones are marked by GFP (green). Scale bar $100 \mu \mathrm{m}$. Quantification of the heterotypic competition assay. Diagram shows the average occupancy of the indicated RNAiloverexpression clones per wing pouch \pm SD. ${ }^{* * * *} P<0.0001$, 
Banreti and Meier

${ }^{* * *} P<0.001,{ }^{* *} P<0.01,{ }^{*} P<0.1$ by Mann-Whitney nonparametric $U$-test. $\mathrm{n}$ depicts the number of wing discs. See Supplemental Information Table for genotypes. (B) Confocal images of wing discs that were immunostained with anti-phospho-JNK. Scale bar $50 \mu \mathrm{m}$. (C) Confocal images of wing discs that were immunostained with Phalloidin and anti-MMP1. Scale bar $50 \mu \mathrm{m}$. Supplemental Information Table for genotypes.

Figure 3. The TNF>JNK>PDK>PDH signalling axis reprograms the metabolism of $N R 2$ loser clones.

(A) Schematic representation of the metabolic reprograming of loser cells by the TNF $>J N K>P D K>P D H$ signalling pathway. Phospho-PDH-specific immunostaining of clones expressing genes-of-interest (goi) and UAS-LacZ. LacZ expression is revealed by anti- $\beta$ Gal staining. Scale bar $25 \mu \mathrm{m}$. (B) Heterotypic clonal analysis. The indicated genes-of-interest (goi) were knocked down or over-expressed (UASPDK-RNAi or UAS-PDH) in GFP-marked clones, and stained for anti-phospho-PDH (ii,iv). Loser clones are marked by GFP (green). Scale bar $100 \mu \mathrm{m}$ (i,iii) or $50 \mu \mathrm{m}$ (ii,iv). (C) Quantification of the heterotypic competition assay. Diagram shows the average occupancy of the indicated RNAiloverexpression clones per wing pouch \pm SD. ${ }^{* * * *} P<0.0001,{ }^{* * *} P<0.001,{ }^{* *} P<0.01,{ }^{*} P<0.1$ by Mann-Whitney nonparametric $U$-test. $\mathrm{n}$ depicts the number of wing discs. See Supplemental Information Table for genotypes.

Figure 4. NR2 controls cell competition by regulating lactate-mediated metabolic coupling between winners and losers.

(A) Schematic summary of our data depicting NR2-assisted regulation of cell competition via lactatemediated metabolic coupling. Heterotypic clonal analysis. The indicated genes-of-interest (goi) were knocked down and over-expressed in GFP-marked clones. For genotypes see Supplementary Data Table. Loser clones are marked by GFP (green). Lactate feeding and treatment with MCT inhibitor was conducted as outlined in the Methods section. (B) Quantification of the heterotypic competition assay. Diagram shows the average occupancy of the indicated RNAi clones per wing pouch, using the indicated conditions. ${ }^{* * *} P<0.0001,{ }^{* * *} P<0.001$, ${ }^{* *} P<0.01$, ${ }^{*} P<0.1$ by Mann-Whitney nonparametric $U$ test. $\mathrm{n}$ depicts the number of wing discs. See Supplemental Information Table for genotypes. 
Banreti and Meier

\section{Figure 5. NR2 is upregulated in supercompetitior Myc-expressing cells.}

(A) Immunostaining of imaginal wing discs and fat body, GFP-marked Myc overexpressing clones. NR2 expression is revealed by antibody specific to the Drosophila NR2 subunit. Scale bars $100 \mu \mathrm{m}$. (B) Mean signal intensity of anti-NR2 specific staining in Myc expressing cells (red) and immediately adjacent wild type cells (black). (C) Anti-Glutamate-specific staining of fat body, Myc overexpressing cells are marked with GFP. Scale bar $100 \mu \mathrm{m}$. See Supplemental Information Table for genotypes.

Figure 6. NR2 is essential for the supercompetitior status of Myc- or RasV12-expressing cells.

(A,B) Heterotypic supercompetitor clonal analysis. Myc (a) and RasV12 (b) expressing clones are marked by GFP. LacZ-RNAi or NR2-RNAi were expressed in clones expressing Myc or RasV12 as described in Figure 1A, left panel. (C) Quantification of the heterotypic supercompetitor clonal assays. Diagram shows the average occupancy of the indicated clones per wing pouch \pm SD. (D) Heatshock-mediated induction of RasV12 clones in the wing pouch caused eclosure-failure and resulted in pupal lethality. Shown are the numbers of eclosed imagoes expressed as the ratio of eclosed imago/total. $\mathrm{N}$ : number of independent experiments, $\mathrm{n}$ : number of animals. Clones were induced as above. Animals were treated with AP5 as outlined in Methods. (E) Homotypic supercompetitor assay. Diagram shows the average occupancy of Myc and RasV12 clones on homotypic background. The indicated genes-of-interest were over-expressed (Myc or RasV12) and knocked-down (LacZ or NR2) throughout the wing pouch as described in Figure 1B (right panel). GFP-marked clones represent pseudoclones. Diagram shows the average occupancy of the indicated clones (heterotypic analysis) or pseudoclones (homotypic analysis) per wing pouch \pm SD. ${ }^{* * *} P<0.0001,{ }^{* * *} P<0.001,{ }^{* *} P<0.01,{ }^{*} P<0.1$ by Mann-Whitney nonparametric $U$-test. $n$ depicts the number of wing discs. (F) Shown are confocal images of wing discs that were immunostained with anti-cleaved DCP1. Scale bar $100 \mu \mathrm{m}$. See Supplemental Information Table for genotypes. 
Banreti and Meier

\section{Supplemental Information}

\section{Figure Legends}

Figure S1. Expression of NR2 in wing discs and salivary glands.

(A) Localisation and expression of NR2 and Dlg1 in the wing disc of third instar larvae was evaluated using the indicated antibodies. Septate junctions are marked with anti-Dlg1. Scale bars $20 \mu \mathrm{m}$ and 10 $\mu \mathrm{m}$. (B) Expression analysis of NR2 in the wing disc of third instar larvae. A protein trap line that carries eGFP in frame with NR2 was used to monitor NR2 expression. Shown is a confocal image of a wing disc stained with anti-GFP (NR2). Scale bar $100 \mu \mathrm{m}$. (C) Expression analysis of NR2 in salivary glands. Antibody staining with anti-NR2 antibodies in salivary glands in which NR2 was downregulated in clones. RNAi clones are marked by GFP. Scale bar $100 \mu \mathrm{m}$. See Supplemental Information Table for genotypes.

\section{Figure S2. Context-dependent elimination of loser clones.}

(A) Heterotypic clonal analysis. The indicated genes were knocked down in GFP-marked clones as depicted in Figure 1D. Scale bar $100 \mu \mathrm{m}$. (B) Homotypic clonal analysis. Dlg1 was knocked down throughout the wing pouch as described in Figure 1F. GFP-marked clones represent pseudo-clones. Scale bar $100 \mu \mathrm{m}$. (C) Homotypic analysis. The indicated genes were knocked down throughout the posterior compartment of the wing pouch. Scale bar $100 \mu \mathrm{m}$. See Supplemental Information Table for genotypes.

Figure S3. NR2 loser clones are eliminated by apoptosis via the Eiger>JNK signalling axis.

(A) Heterotypic clonal analysis of third instar wing discs. PucLacZ, expression as a marker of JNK activity was revealed with anti- $\beta$ Gal staining. Scale bar $50 \mu \mathrm{m}$. (B) Confocal images of wing discs that were immunostained with anti-cleaved DCP1. Scale bar $50 \mu \mathrm{m}$. See Supplemental Information Table for genotypes.

Figure S4. NR2 controls cell competition by regulating lactate-mediated metabolic coupling between winners and losers.

(A) Confocal images of GFP-marked and anti-phospho-PDH (reading out its inactivation) stained wing pouches. Scale bar $50 \mu \mathrm{m}$. (B) Fluorescent intensities of phospho-PDH (black) and GFP (green) are 
Banreti and Meier

measured by ImageJ software at the yellow lines. (C) Pearson's correlation analysis of phospho-PDH and GFP. d, Quantification of the average size of mitochondria stained with MitoTracker Red. (E) Confocal images of third instar imaginal wing discs that were immunostained for cleaved DCP1 as a readout of caspase activation and apoptosis. Scale bar $50 \mu \mathrm{m}$. See Supplemental Information Table for genotypes.

Figure S5. MCT1 is upregulated in NR2 loser clones.

Confocal images of anti-MCT1 stained wing pouches. Scale bar $20 \mu \mathrm{m}$. See Supplemental Information Table for genotypes.

Figure S6. Myc-expressing supercompetitior cells reprogram the metabolism of neighbouring wild-type cells.

(A) Confocal images of dissected wing pouches stained for anti-phospho-PDH (reading out its inactivation). Scale bar $50 \mu \mathrm{m}$. (B) Fluorescent intensities of phospho-PDH (black) and GFP (green) are measured by ImageJ software at the yellow lines. (C) Pearson's correlation analysis of phospho$\mathrm{PDH}$ and GFP.

Figure S7. NR2 is essential for the supercompetitior status of RasV12-expressing cells.

Confocal images of dissected wing pouches stained for anti-phospho-PDH. Scale bar $20 \mu \mathrm{m}$. b, Fluorescent intensities of phospho-PDH (black) and GFP (green) are measured by ImageJ software at the yellow lines.

Supplemental Information Table: Drosophila genotypes used in this study Main Figures

\begin{tabular}{|c|c|c|}
\hline Figure: & Panel: & Genotype: \\
\hline 1 & C & $\begin{array}{ll}\text { - } & \text { hsFlp;UAS-LacZ-RNAi/+;Act<CD2<Gal4,UAS-nEGFP/+ } \\
\text { - } & \text { hsFIp;+/+;Act<CD2<Gal4,UAS-nEGFP/NR2 }{ }^{G D 3196}-R N A i \\
\text { - } & \text { hsFlp;UAS-NR2-RNAi/+;Act<CD2<Gal4,UAS-nEGFP/+ }\end{array}$ \\
\hline 1 & D & 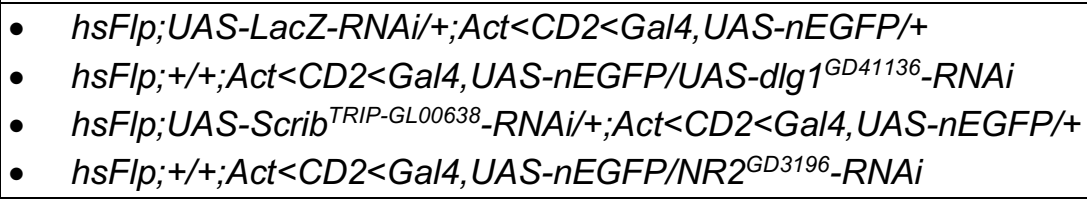 \\
\hline
\end{tabular}


Banreti and Meier

\begin{tabular}{|c|c|c|}
\hline & & 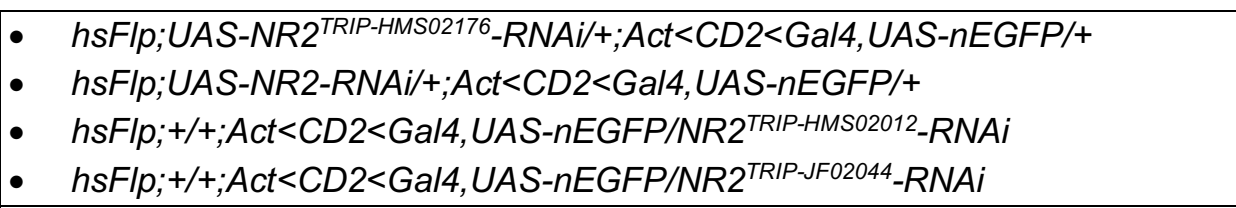 \\
\hline 1 & $E$ & $\begin{array}{ll}- & \text { hsFlp;UAS-LacZ-RNAi/nub-Gal4;Ubi- } \\
& \text { p63E<FRT.STOP.FRT<Stringer(nEGFP)/+ } \\
\text { - } & \text { hsFlp;+/nub-Gal4;Ubi-p63E<FRT.STOP.FRT<Stringer(nEGFP)/NR2 }{ }^{\text {GD3196_ }} \\
& \text { RNAi }\end{array}$ \\
\hline 1 & $F$ & 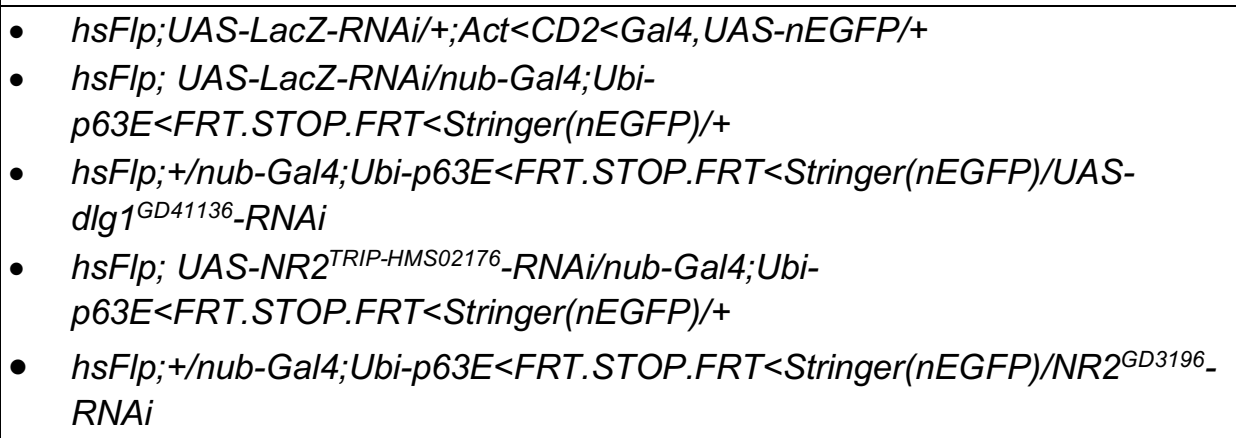 \\
\hline 1 & $\mathbf{G}$ & 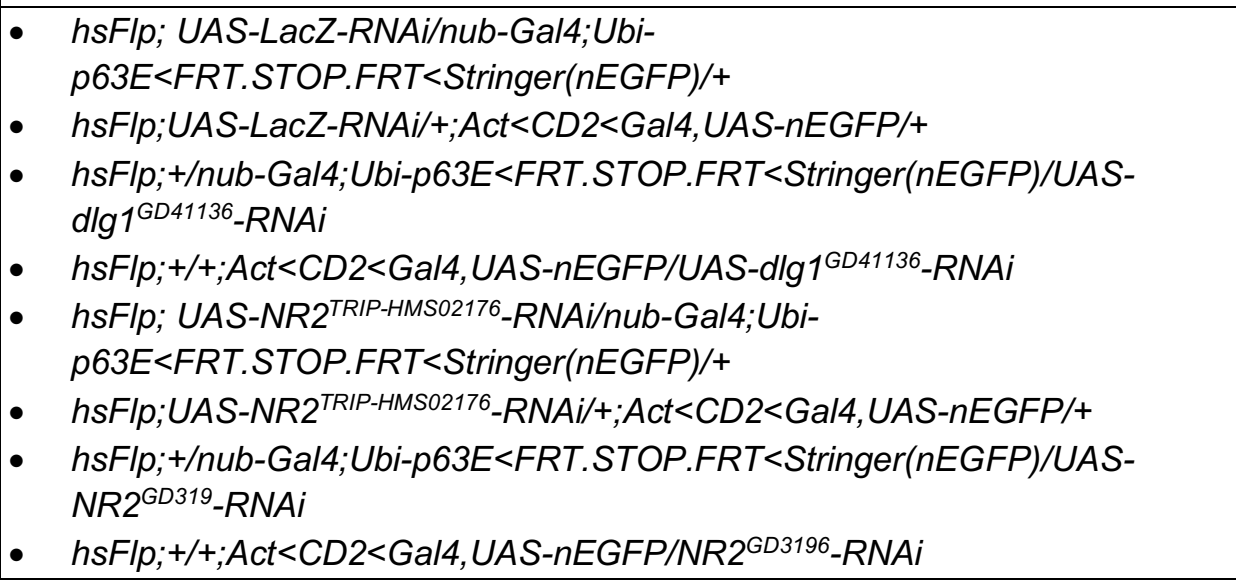 \\
\hline 1 & $\mathbf{H}$ & $\begin{array}{ll}\text { - } & \text { hsFlp;UAS-LacZ-RNAi/+;Act<CD2<Gal4,UAS-nEGFP/+ } \\
\text { - } & \text { hsFlp;+/+;Act<CD2<Gal4,UAS-nEGFP/NR2 } \\
\text { TRIP-HMS02012-RNAi }\end{array}$ \\
\hline 2 & $\mathbf{A}$ & 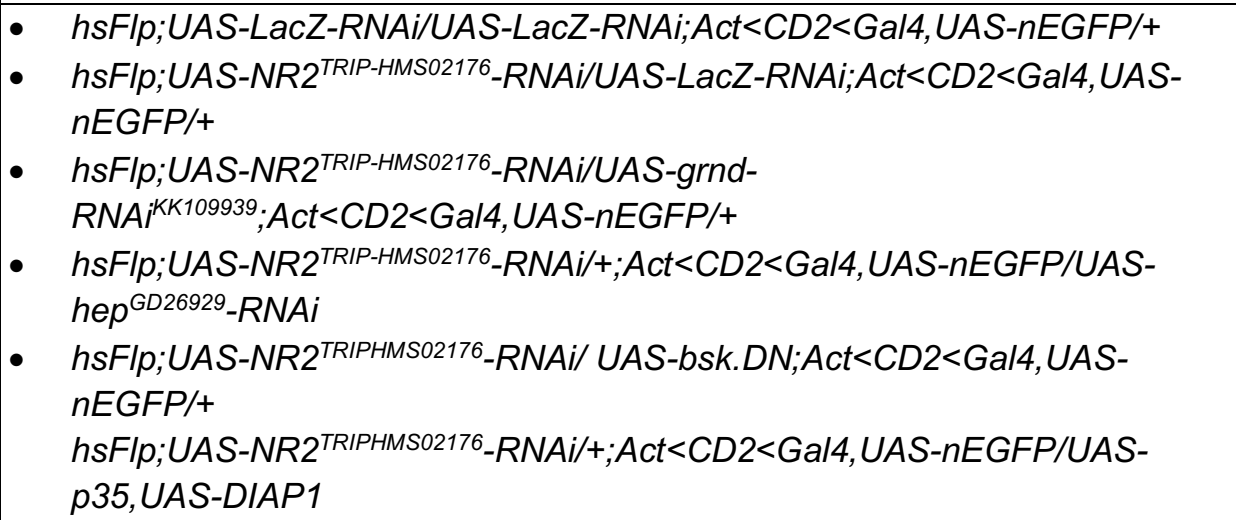 \\
\hline 2 & B & $\begin{array}{ll}\text { - } & \text { hsFlp;UAS-LacZ-RNAi/UAS-LacZ-RNAi;Act<CD2<Gal4,UAS-nEGFP/+ } \\
\text { - } & \text { hsFlp;UAS-NR2TRIP-HMSO2176-RNAi/UAS-LacZ-RNAi;Act<CD2<Gal4,UAS- } \\
& \text { nEGFP/+ }\end{array}$ \\
\hline 2 & C & $\begin{array}{ll} & \text { hsFlp;UAS-LacZ-RNAi/UAS-LacZ-RNAi;Act<CD2<Gal4,UAS-nEGFP/+ } \\
\text { - } & \text { hsFlp;UAS-NR2TRIP-HMS02176-RNAi/UAS-LacZ-RNAi;Act<CD2<Gal4,UAS- } \\
& \text { nEGFP/+ }\end{array}$ \\
\hline 3 & A & hsFlp;UAS-LacZ-RNAi/UAS-LacZ-RNAi;Act<CD2<Gal4,UAS-nEGFP/+ \\
\hline
\end{tabular}


Banreti and Meier

\begin{tabular}{|c|c|c|}
\hline & & 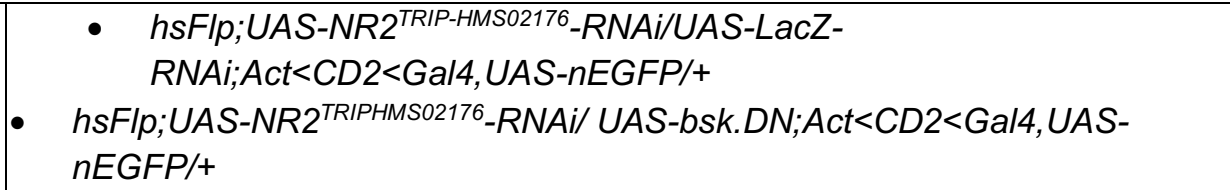 \\
\hline 3 & B,C & 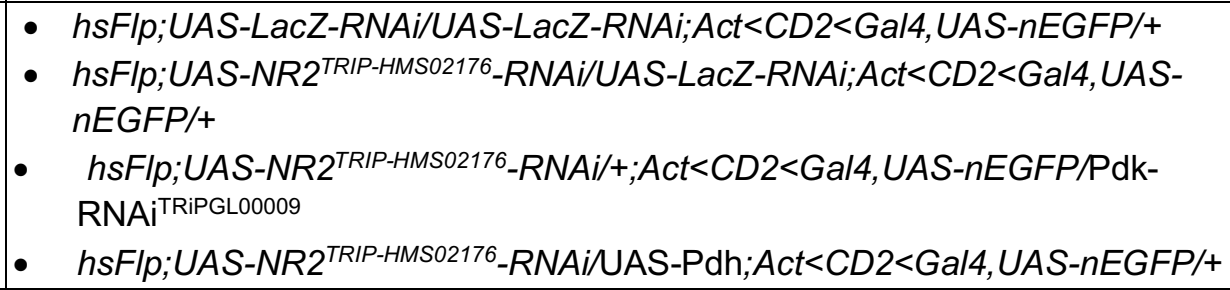 \\
\hline 4 & $A, B$ & 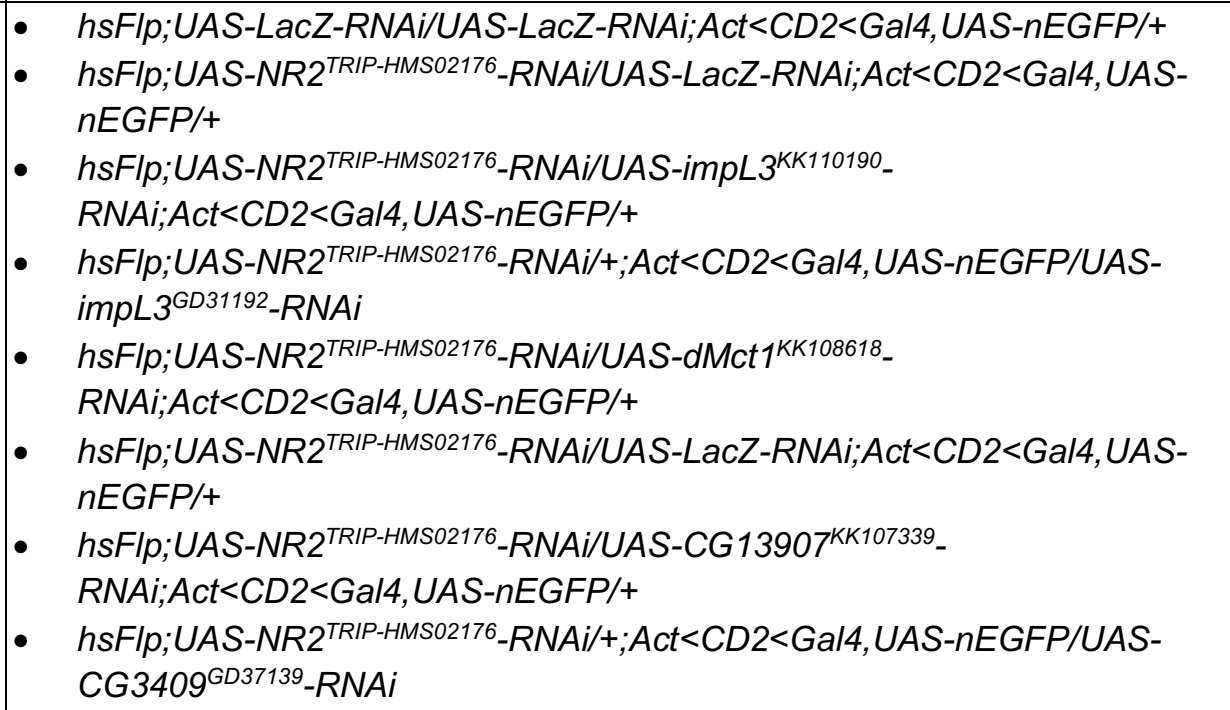 \\
\hline 5 & & - $\quad$ hsFlp;UAS-Myc/+;Act<CD2<Gal4,UAS-nEGFP/+ \\
\hline \multirow[t]{5}{*}{6} & A & 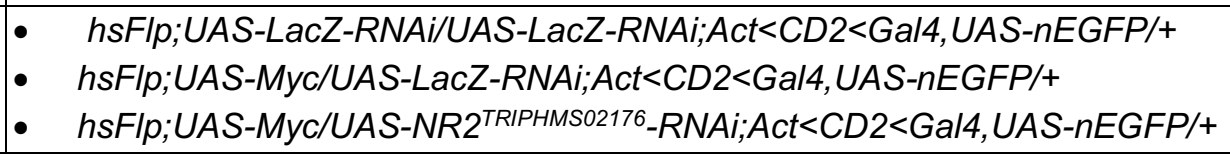 \\
\hline & B & $\begin{array}{ll}\bullet & \text { hsFlp;UAS-LacZ-RNAi/UAS-LacZ-RNAi;Act<CD2<Gal4,UAS-nEGFP/+ } \\
\bullet & \text { hsFlp;UAS-Ras85D.V12/UAS-LacZ-RNAi;Act<CD2<Gal4,UAS-nEGFP/+ } \\
\text { - } & \text { hsFlp;UAS-Ras85D.V12/UAS-NR2 } \\
& \text { nEGFIPHMS02176-RNAi;Act<CD2<Gal4,UAS- }\end{array}$ \\
\hline & $\mathbf{C}$ & 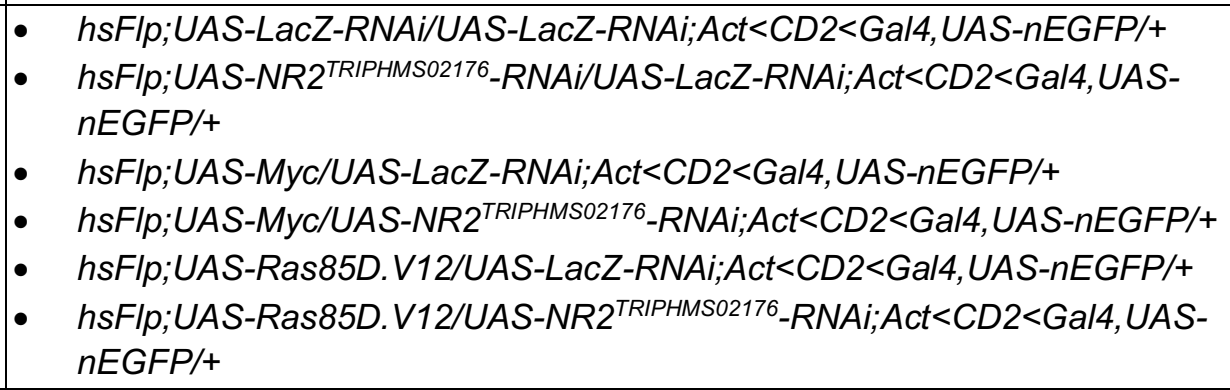 \\
\hline & D & $\begin{array}{ll}\bullet & \text { hsFlp;UAS-LacZ-RNAi/UAS-LacZ-RNAi;Act<CD2<Gal4,UAS-nEGFP/+ } \\
\bullet & \text { hsFlp;UAS-Ras85D.V12/UAS-LacZ-RNAi;Act<CD2<Gal4,UAS-nEGFP/+ } \\
\text { - } & \text { hsFIp;UAS-NR2TRIPHMS02176_RNAi/UAS-LacZ-RNAi;Act<CD2<Gal4,UAS- } \\
& n E G F P /+ \\
\text { - } & \text { hsFlp;UAS-Ras85D.V12/UAS-NR2 } \\
& n E G F P /+\end{array}$ \\
\hline & $\mathbf{E}$ & - $\quad$ hsFlp;UAS-LacZ-RNAi/+;Act<CD2<Gal4,UAS-nEGFP/+ \\
\hline
\end{tabular}


Banreti and Meier

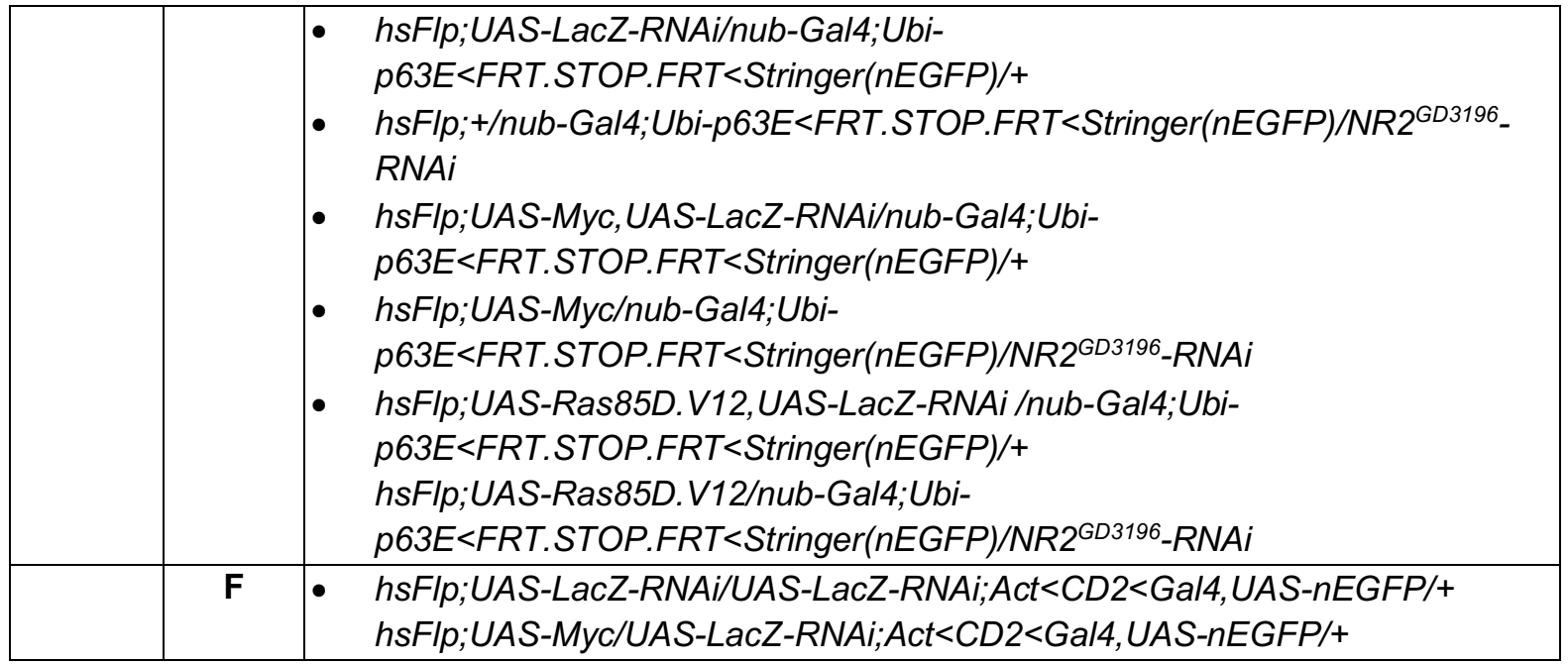

\section{Supplementary Data Figures}

\begin{tabular}{|c|c|c|}
\hline S1 & A & - $\quad W 1118$ \\
\hline S1 & B & - $\quad$ NR2 $2^{M I 09281-G F S T F .2 ;+;+}$ \\
\hline S1 & C & 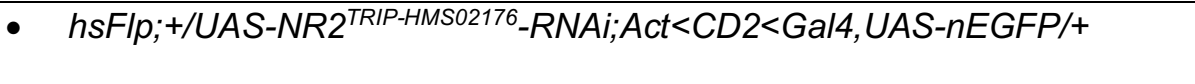 \\
\hline S2 & A & 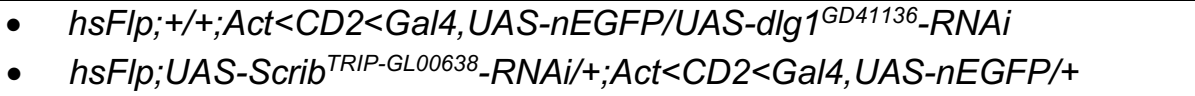 \\
\hline S2 & B & $\begin{array}{l}\text { - } \quad \text { hsFlp;+/nub-Gal4;Ubi-p63E<FRT.STOP.FRT<Stringer(nEGFP)/UAS- } \\
\text { dlg1GD41136_RNAi }\end{array}$ \\
\hline S2 & C & $\begin{array}{ll}\text { - } & \text { w1118;UAS-GFP/LacZ-RNAi;hh-Gal4/+ } \\
\text { - } & \text { w1118;UAS-GFP/ UAS-NR2 } \\
\text { TRIP-HMS02176_RNAi;hh-Gal4/+ }\end{array}$ \\
\hline S3 & A & 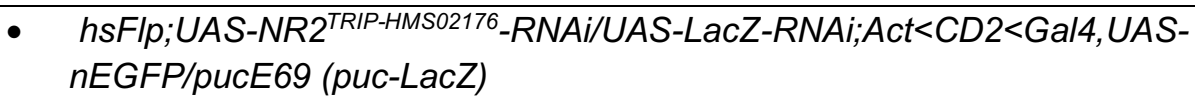 \\
\hline S3 & B & 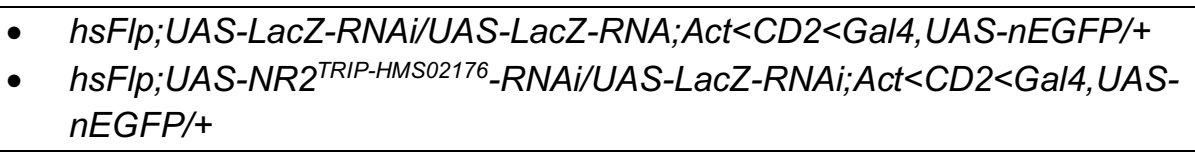 \\
\hline S4 & A & 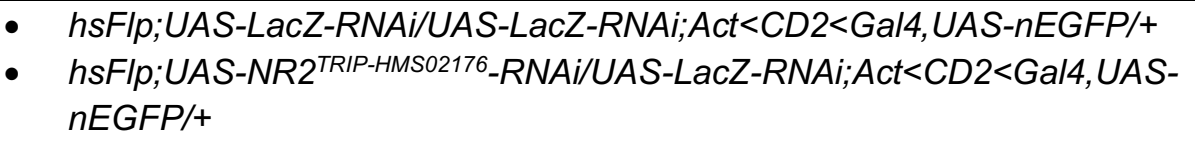 \\
\hline S5 & B-D & 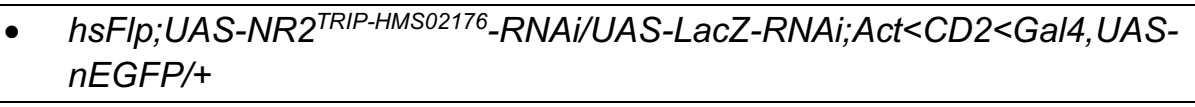 \\
\hline S4 & $\mathbf{E}$ & 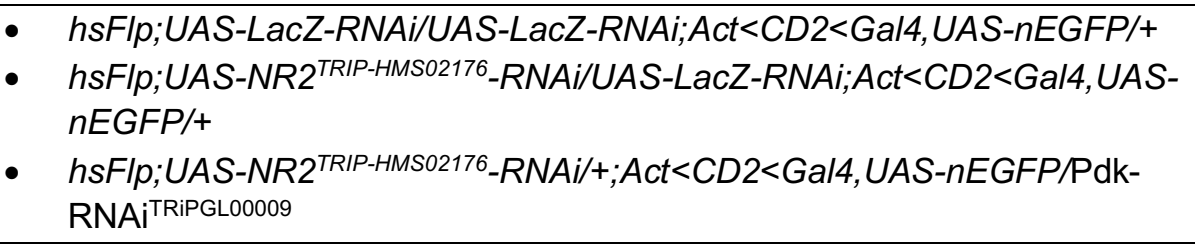 \\
\hline S5 & & 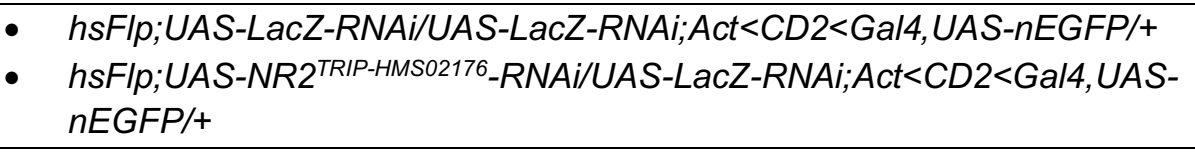 \\
\hline
\end{tabular}


Banreti and Meier

\begin{tabular}{|c|c|c|}
\hline S6 & $\mathbf{A}$ & - $\quad$ hsFlp;UAS-LacZ-RNAi/UAS-LacZ-RNAi;Act<CD2<Gal4,UAS-nEGFP/+ \\
\hline S6 & B-D & hsFlp;UAS-Myc/UAS-LacZ-RNAi;Act<CD2<Gal4,UAS-nEGFP/+ \\
\hline S7 & & 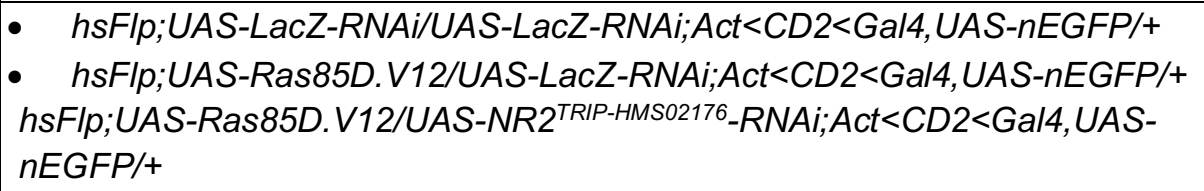 \\
\hline
\end{tabular}


A

Heterotypic competition assay

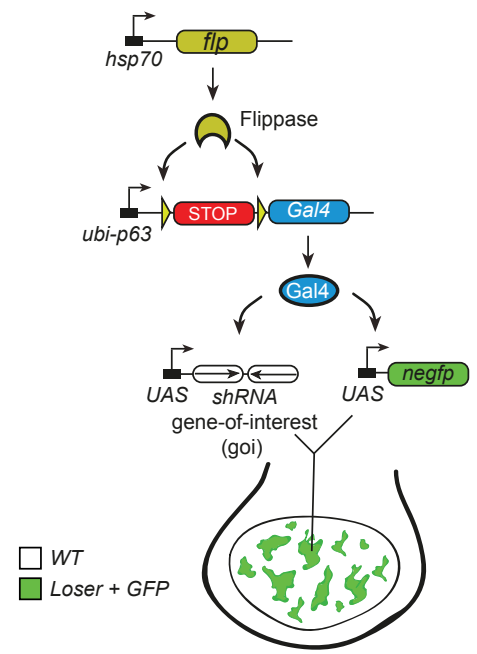

hsFIp;;Act|CD2|Gal4

$>$ UAS-negfp >UAS-gene-of-interest (goi)
Homotypic competition assay
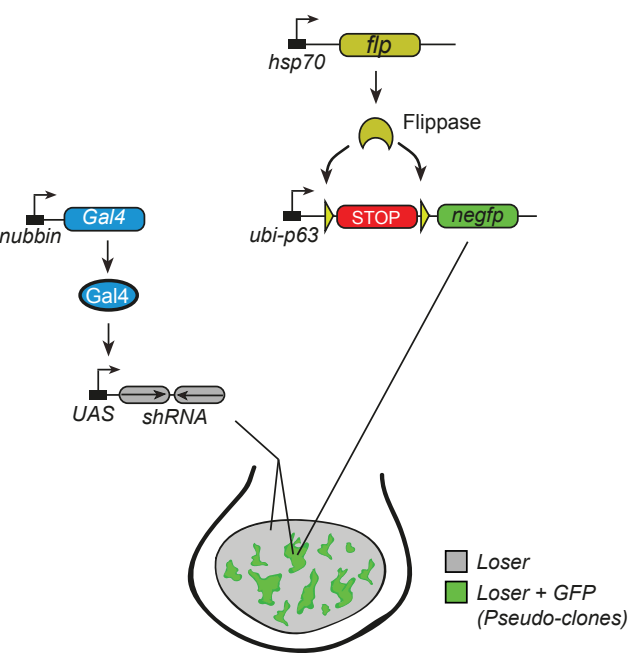

hsFIp;;Ubip63|CD2|nEGFP

nub-Gal4>UAS-gene-of-interest (goi)
B
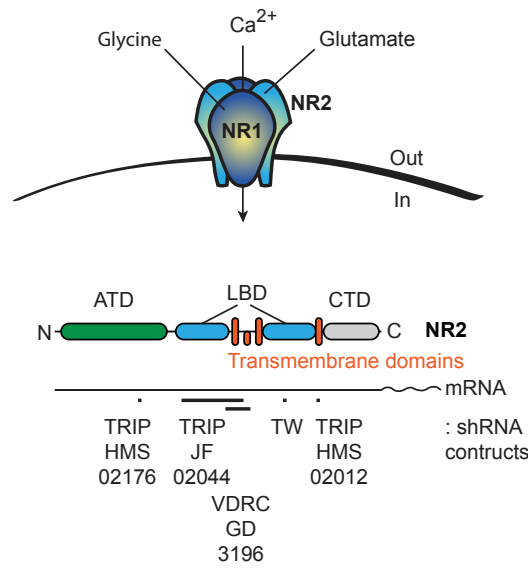

D Heterotypic clonal analysis

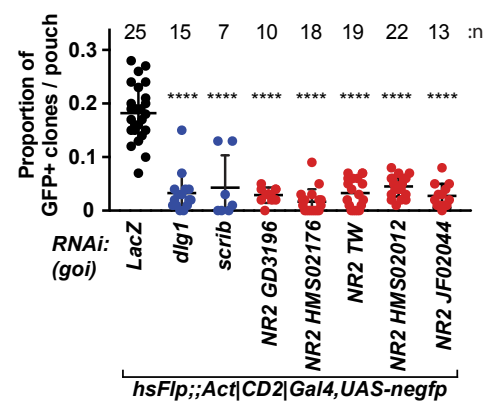

G Relative growths under homovs. heterotypic settings

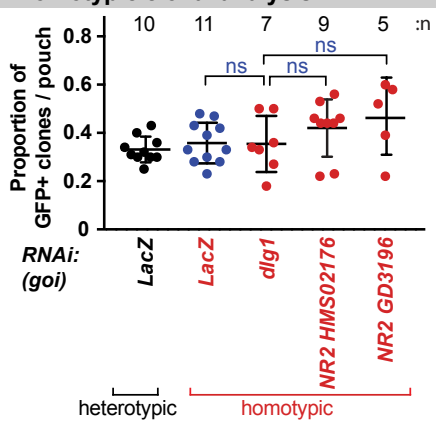

\section{F Homotypic clonal analysis}

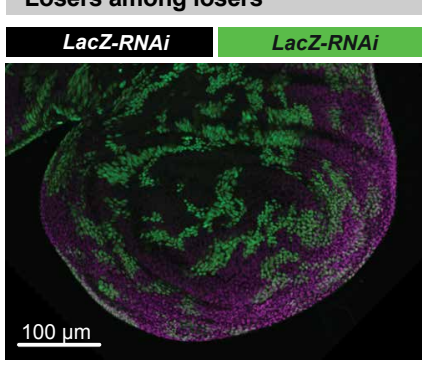

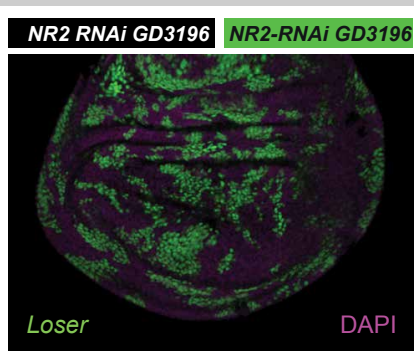

H Loser among winners

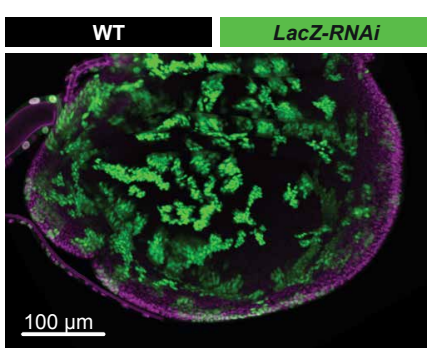

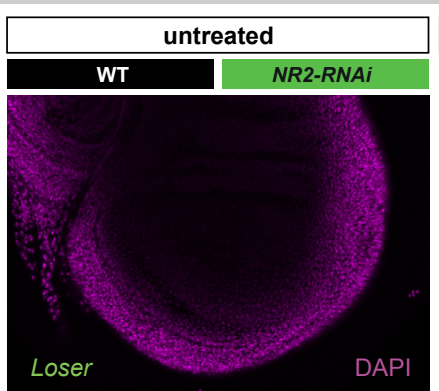

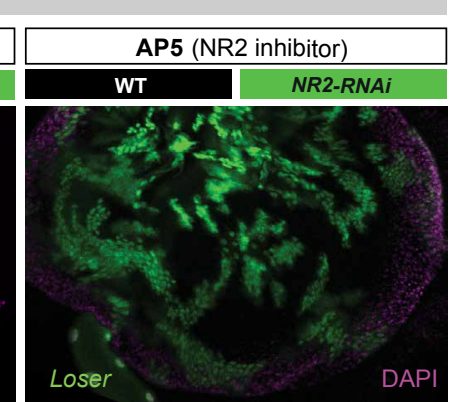

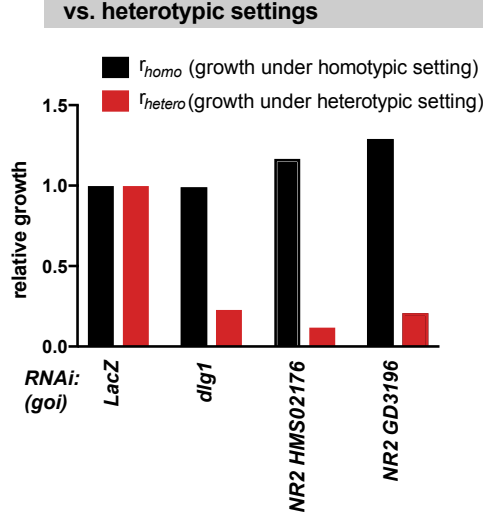

I Loser among winners - AP5 rescue

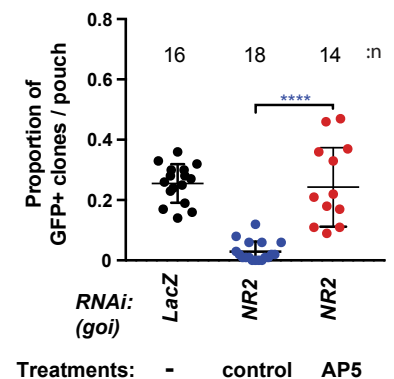




\section{A Losers among winners - Epistasis analysis of clonal elimination}
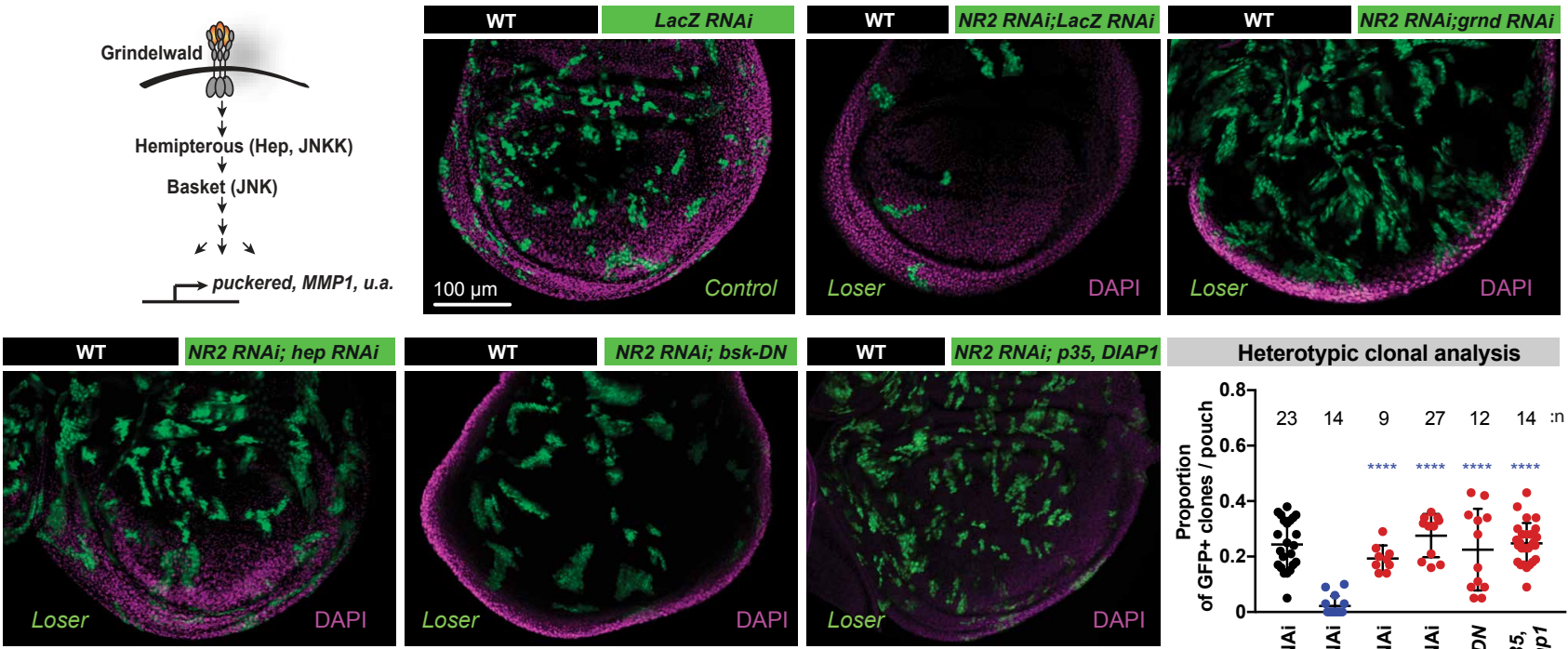

B Losers among winners - JNK activation
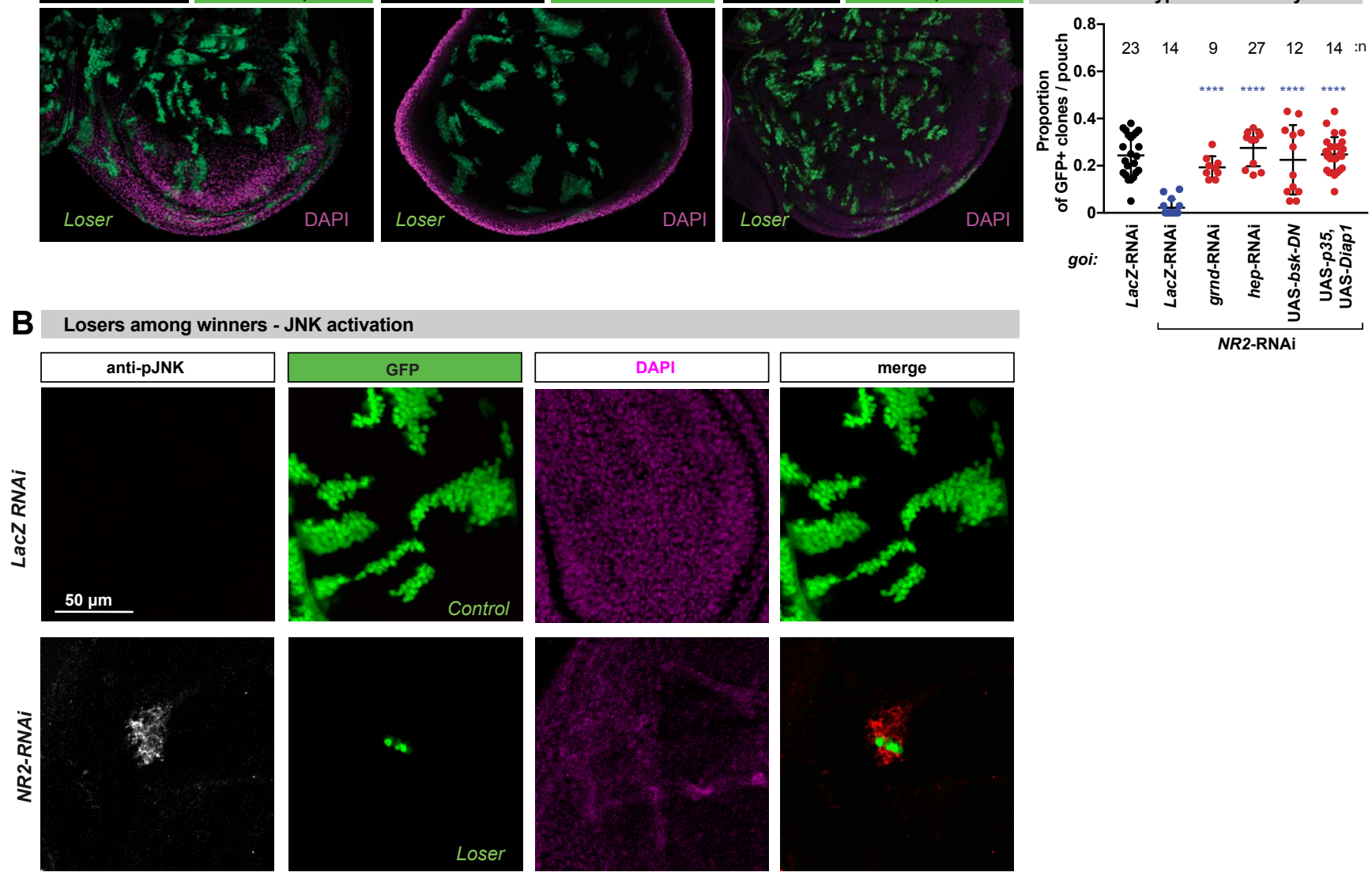

C Losers among winners - MMP1 expression (JNK target)
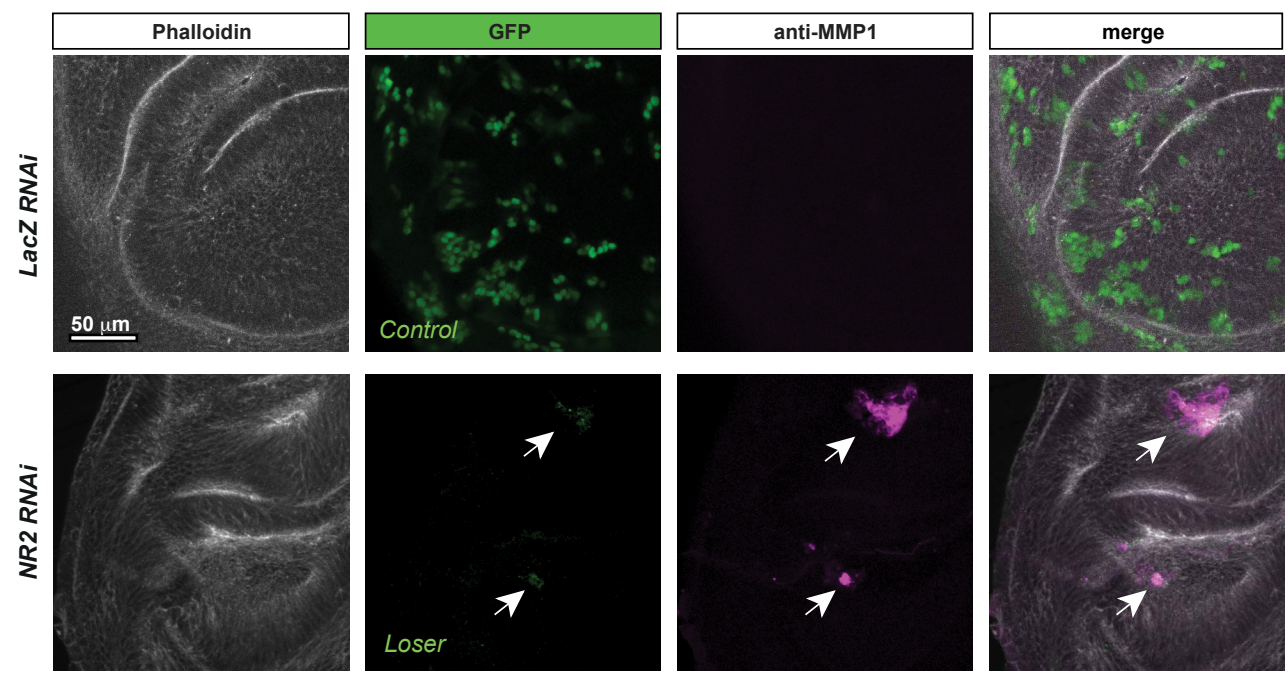

Figure 2. Banreti and Meier, 2019 
bioRxiv preprint doi: https://doi.org/10.1101/2020.02.11.943498; this version posted February 12, 2020. The copyright holder for this preprint (which was not certified by peer review) is the author/funder. All rights reserved. No reuse allowed without permission.

A Losers among winners - JNK-mediated PDH inactivation

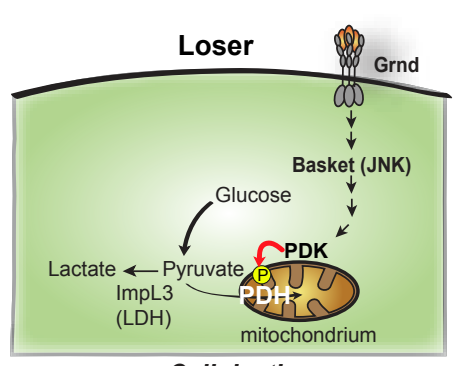

Cell death
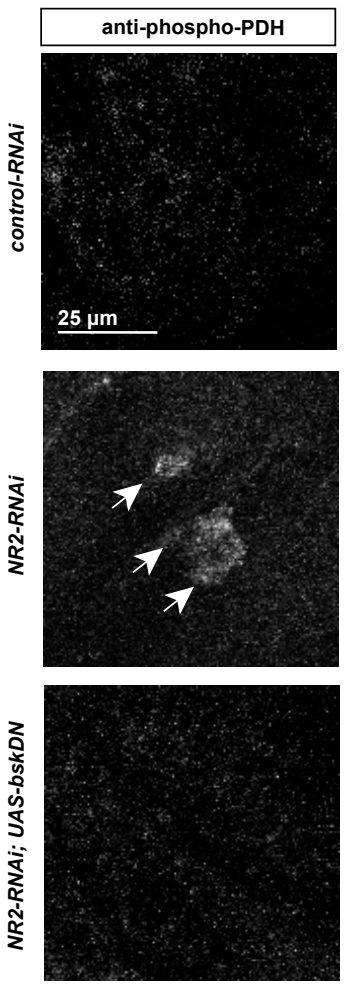
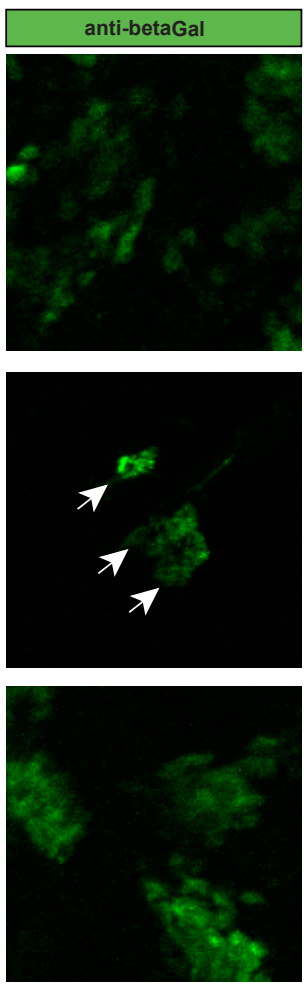
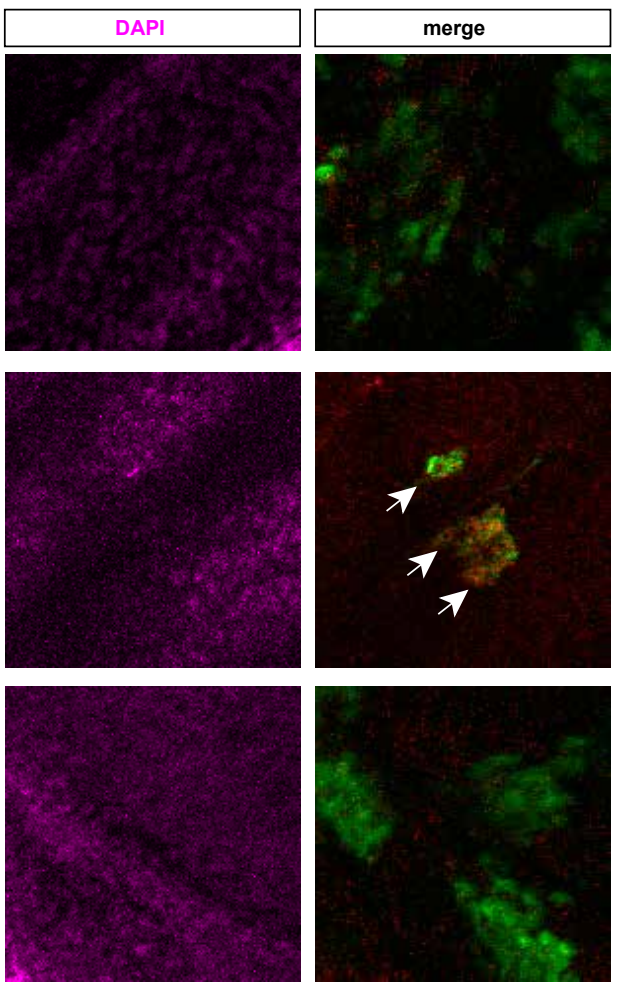

B

NR2 losers among WT - Rescue via metabolism modulation
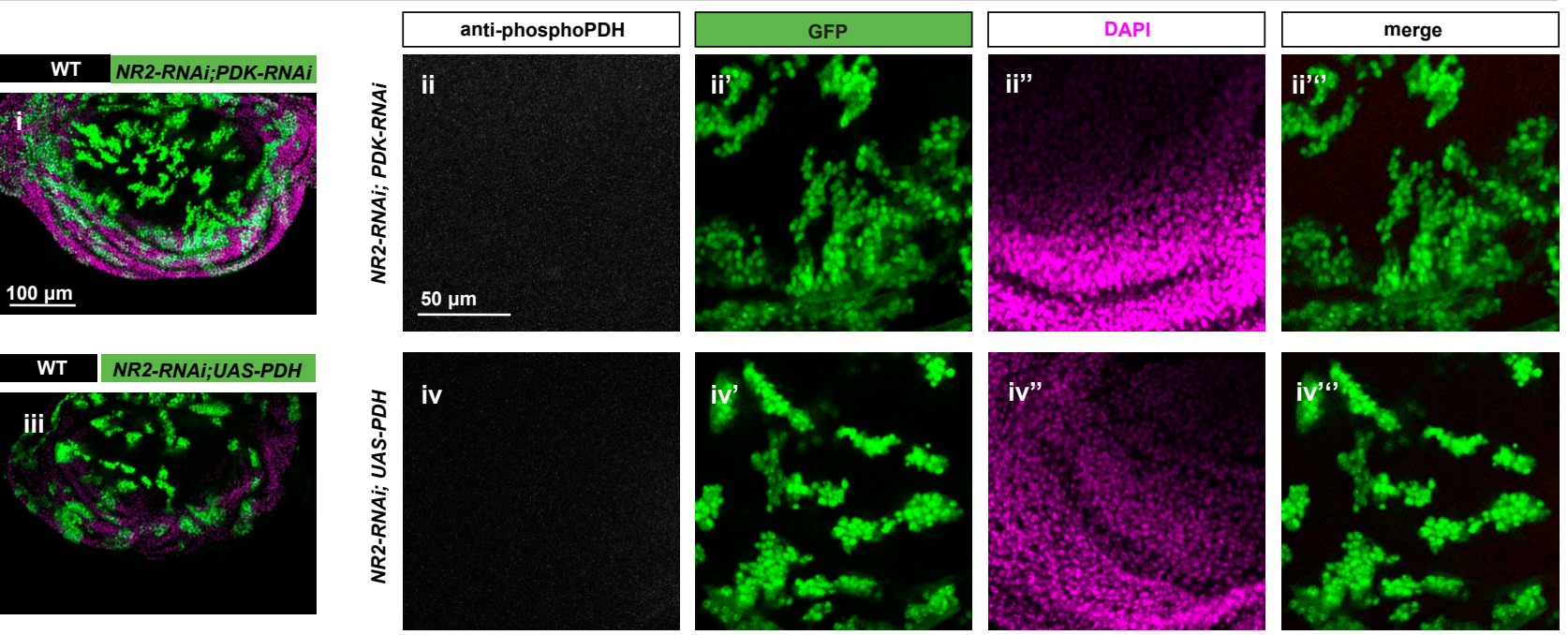

C Heterotypic clonal analysis

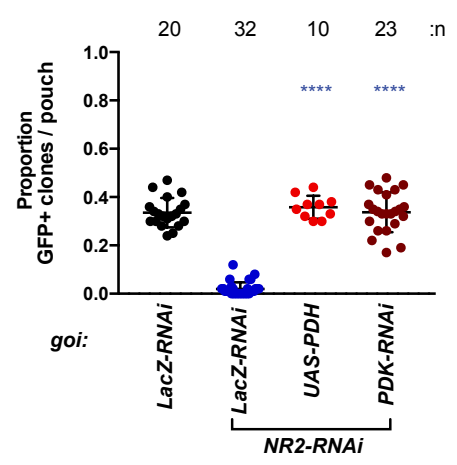

Figure 3. Banreti and Meier, 2019

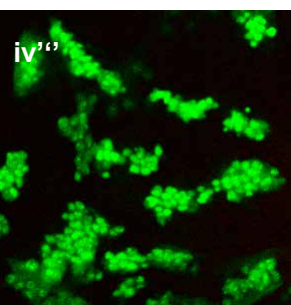


A Heterotypic clonal analysis
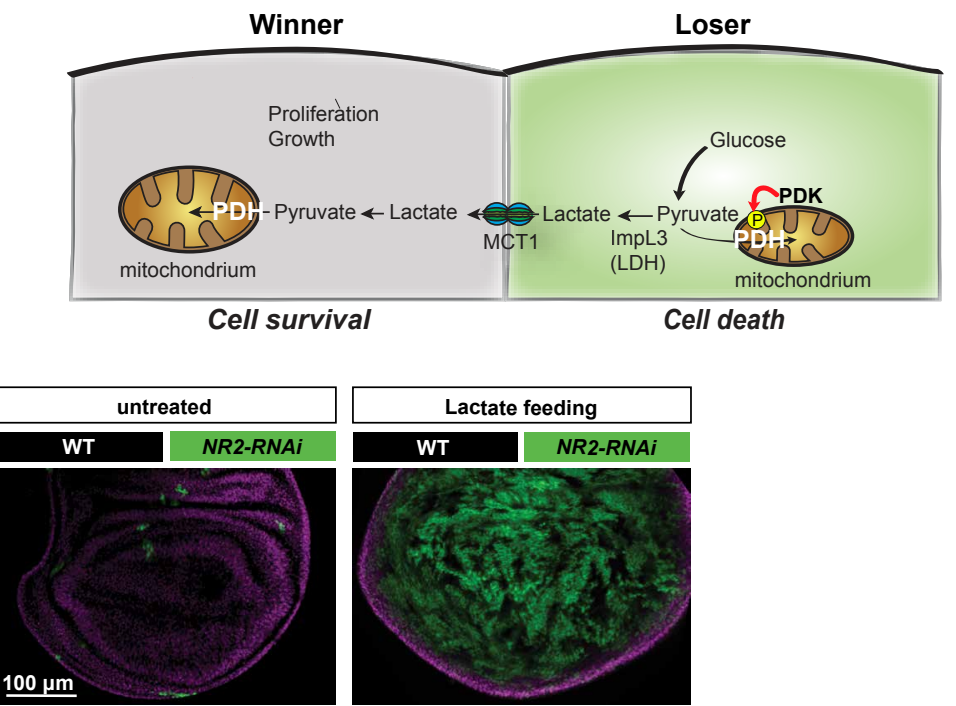

Lactate feeding

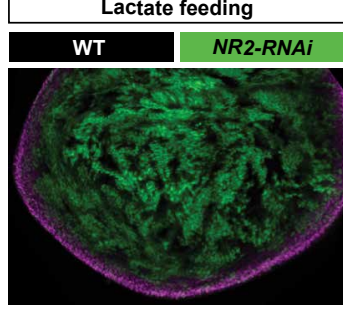

WT NR2-RNAi;ImpL3-RNAi
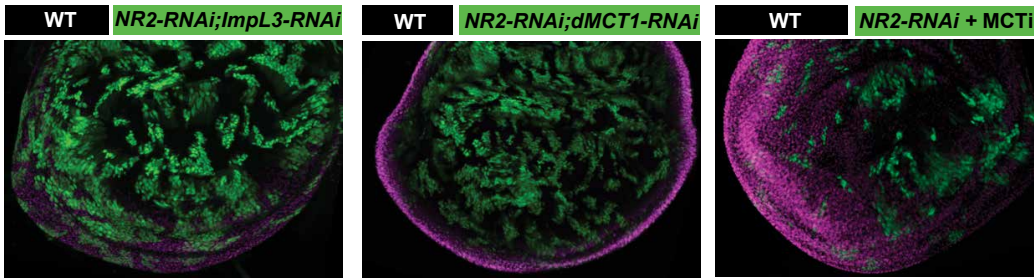

B Heterotypic clonal analysis

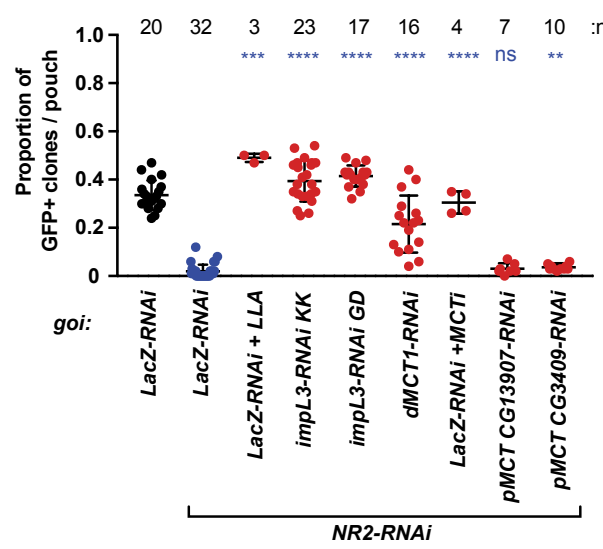

Figure 4. Banreti and Meier, 2019 
bioRxiv preprint doi: https://doi.org/10.1101/2020.02.11.943498; this version posted February 12, 2020. The copyright holder for this preprint (which was not certified by peer review) is the author/funder. All rights reserved. No reuse allowed without permission.

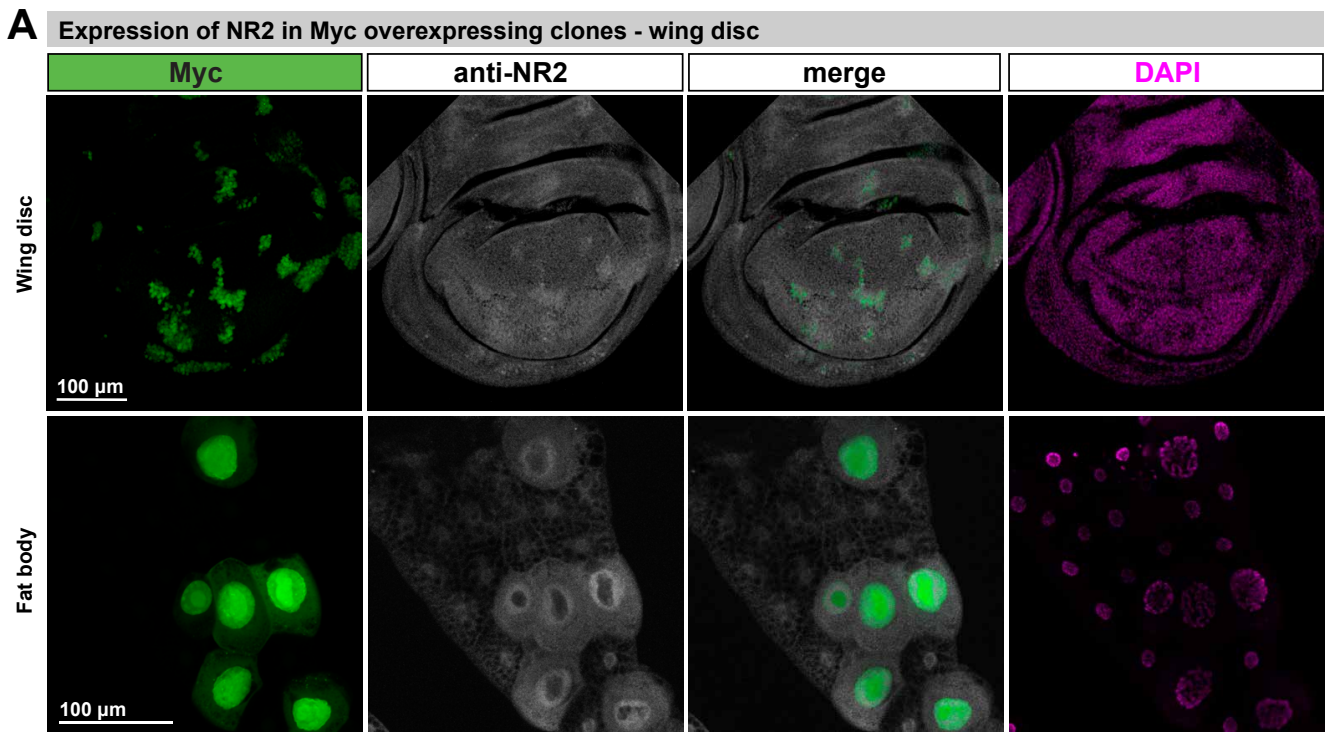

B

NR2 expression levels of Myc- and surrounding wild-type cell populations

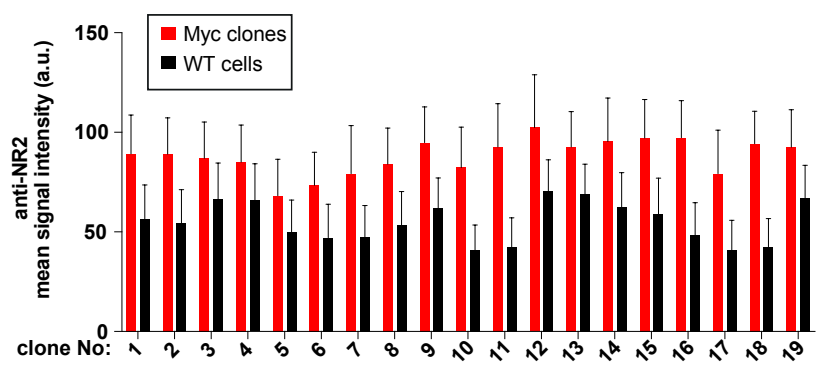

Glutamate (NR2 ligand) staining in Myc overexpressing clones - Fat body

\begin{tabular}{|c|c|c|c|}
\hline Myc & anti-Glutamate & merge \\
\hline & & DAPI \\
\hline $100 \mu \mathrm{m}$
\end{tabular}

Figure 5. Banreti and Meier, 2019 
A

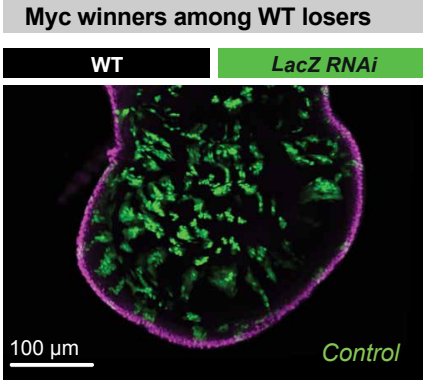

B

RasV12 winners among WT losers

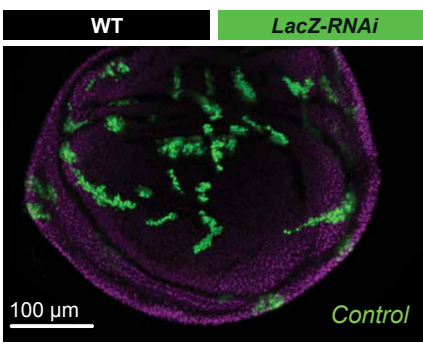

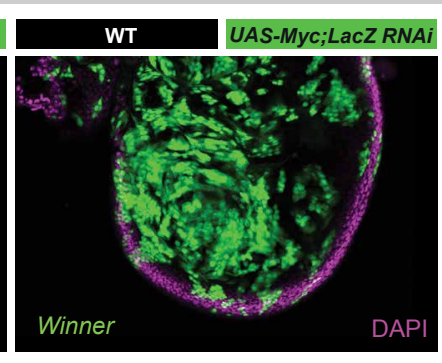

DAPI

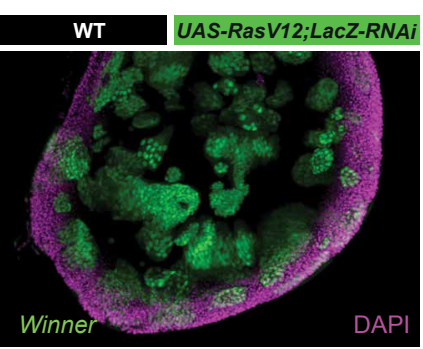

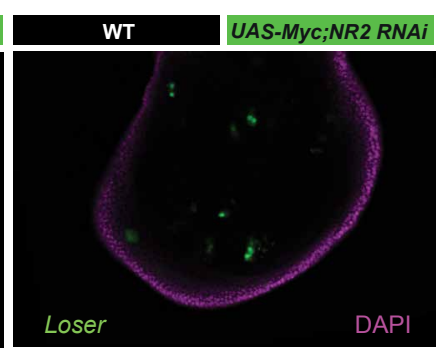

WT

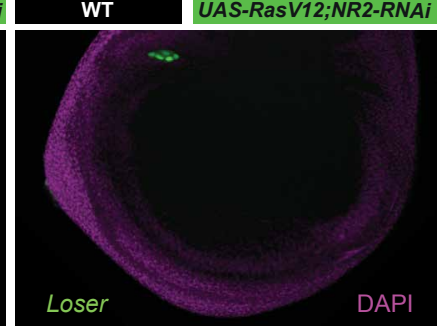

C Heterotypic clonal analysis

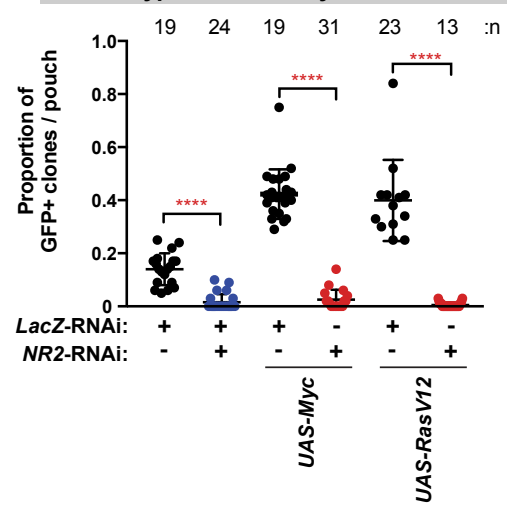

D Eclosure from puapae (survival)

$\begin{array}{ccccc}13 & 14 & 16 & 10 & \text { :N experiments }\end{array}$

$\begin{array}{lllll}848 & 549 \quad 1366 \quad 720 & \text { :n animals }\end{array}$

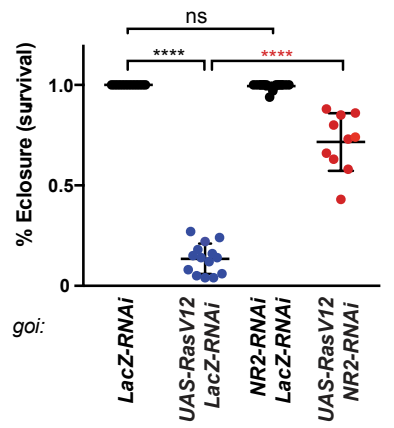

E Homotypic clonal analysis

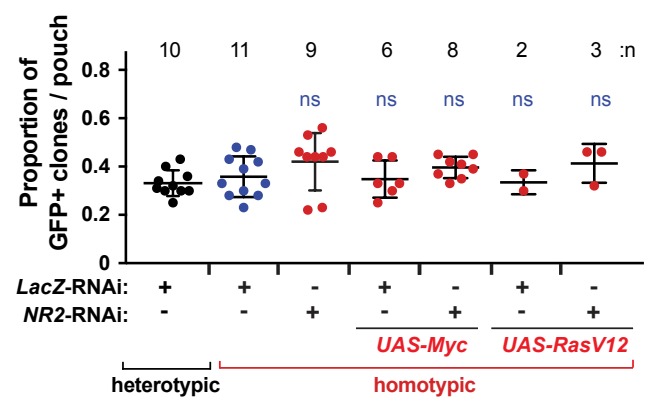

$\mathbf{F}$

Myc winners among WT cells - Caspase activation
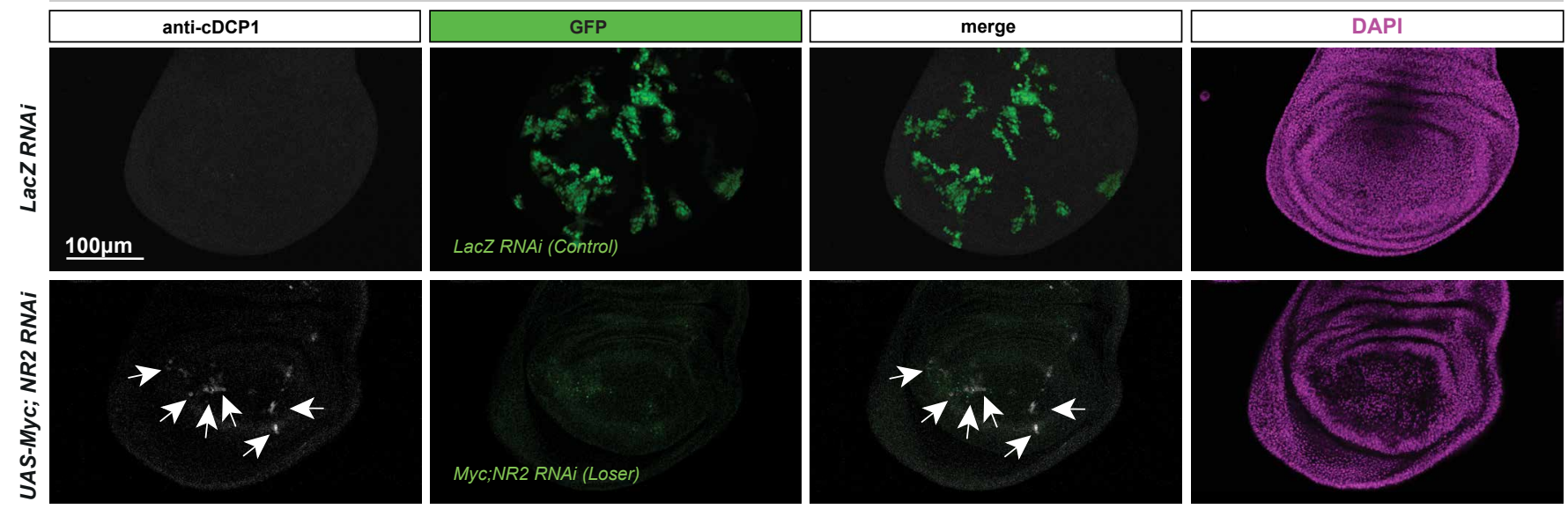

Figure 6. Banreti and Meier, 2019 
bioRxiv preprint doi: https://doi.org/10.1101/2020.02 11.943498; this version posted February 12, 2020. The copyright holder for this preprint (which was not certified by peer review) is the author/funder. All rights reserved. No reuse allowed without permission.
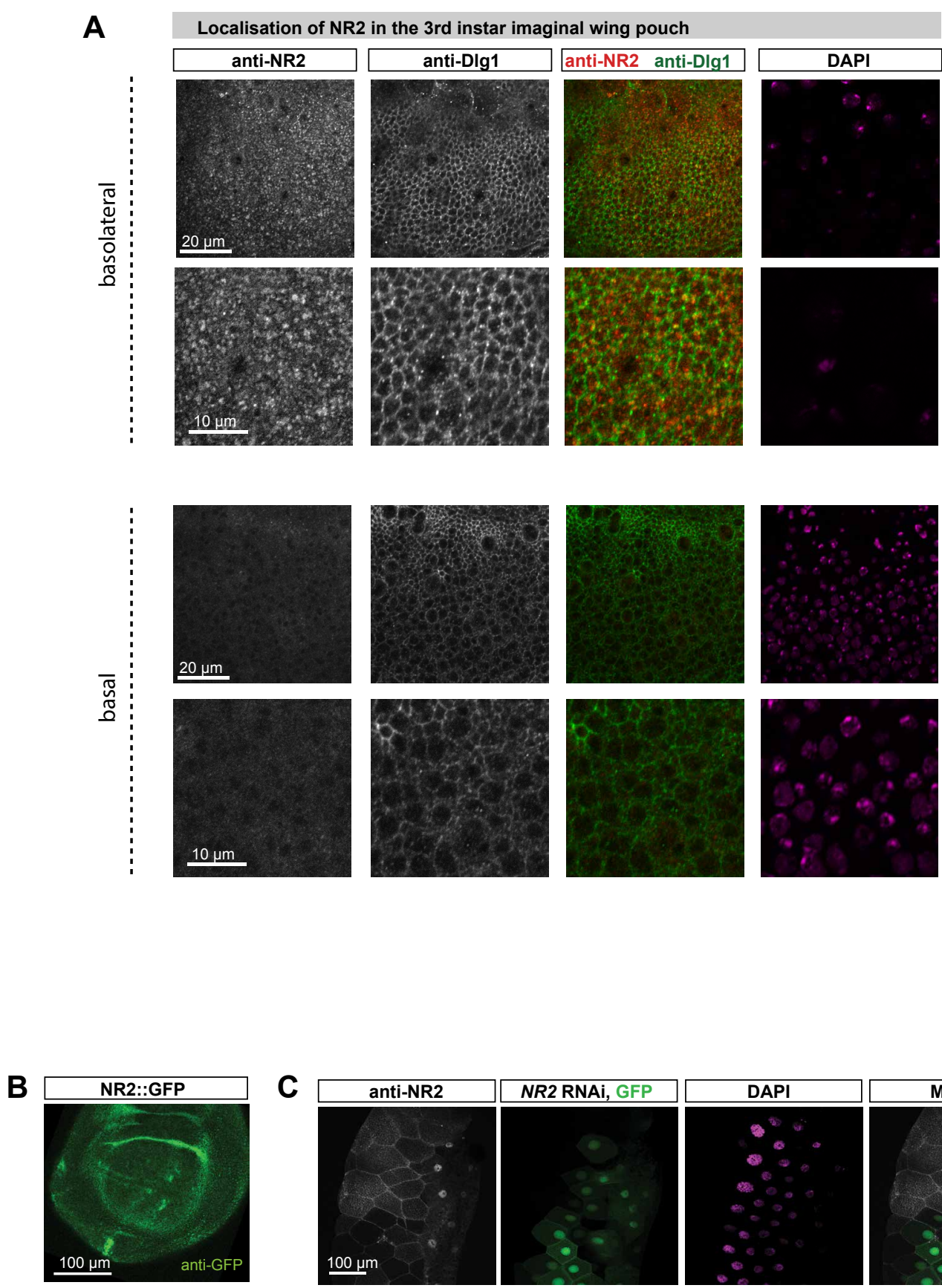

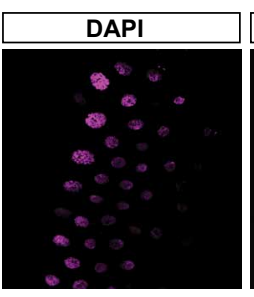

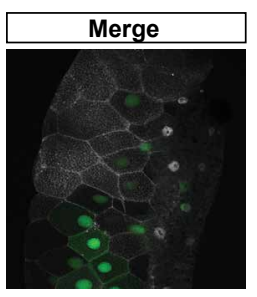

Figure S1.

Banreti and Meier, 2019 
bioRxiv preprint doi: https://doi.org/10.1101/2020 02 11.943498; this version posted February 12, 2020. The copyright holder for this preprint (which was not certified by peer review) is the author/funder. All rights reserved. No reuse allowed without permission.

A Losers among winners
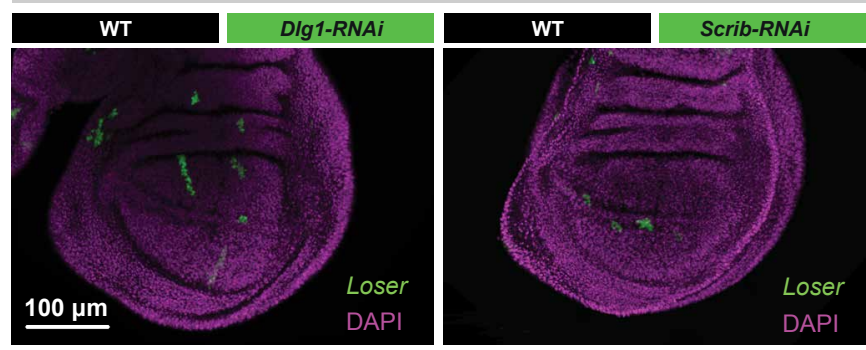

C Losers among losers (compartment-wide expression)

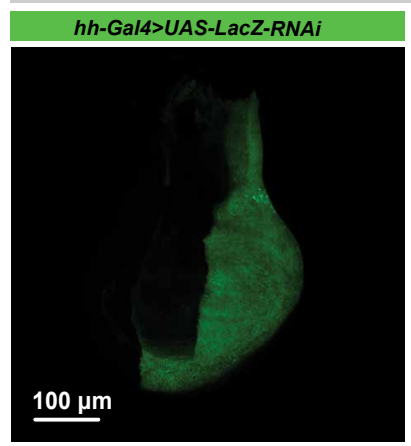

B Losers among losers

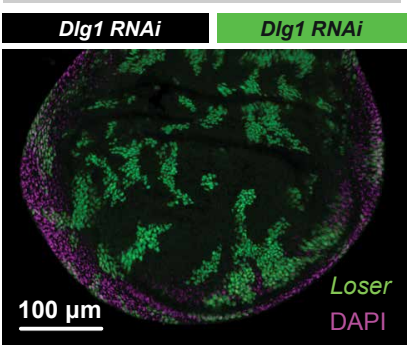

Figure S2.

Banreti and Meier, 2019 
A Losers among winners - JNK activation
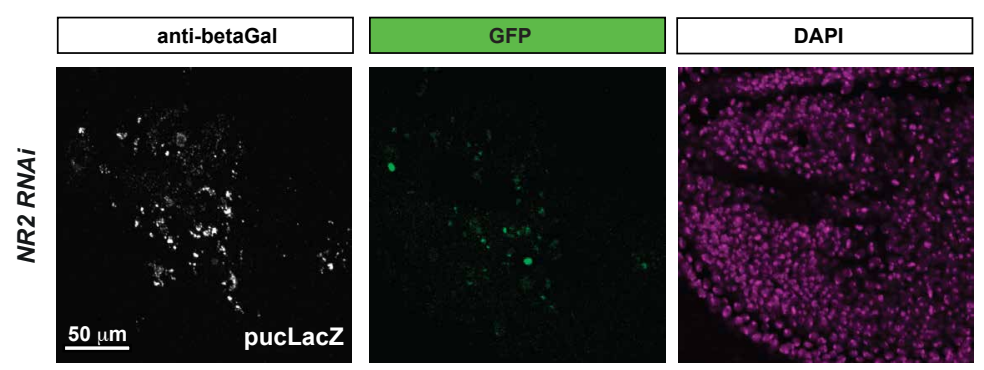

merge

B Losers among winners - Caspase activation
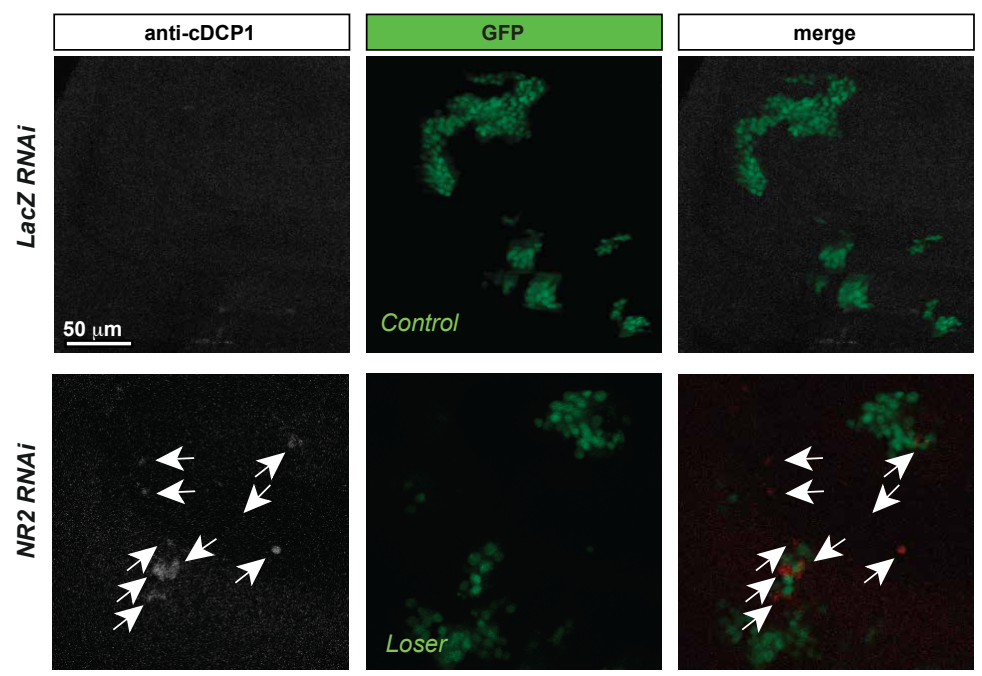

Figure S3.

Banreti and Meier, 2019 
bioRxiv preprint doi: https://doi.org/10.1101/2020.02.11.943498; this version posted February 12, 2020. The copyright holder for this preprint (which was not certified by peer review) is the author/funder. All rights reserved. No reuse allowed without permission.

A Losers among winners - PDH inactivation
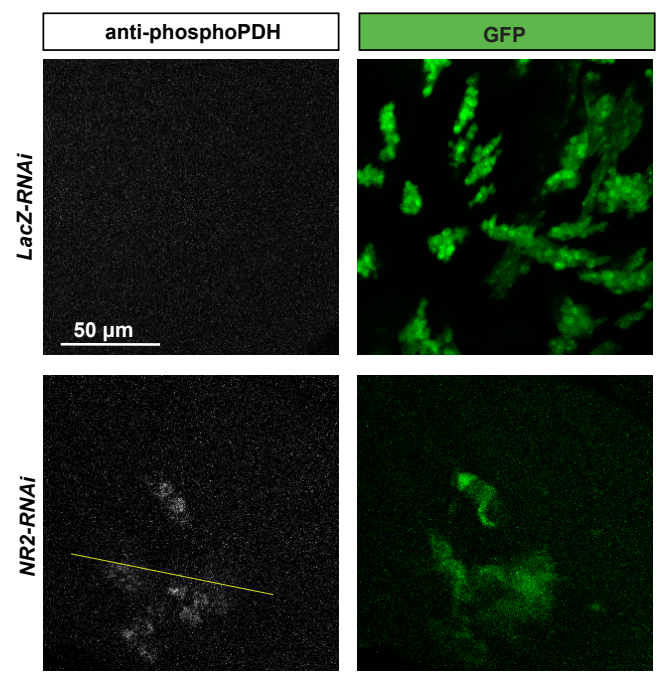

B

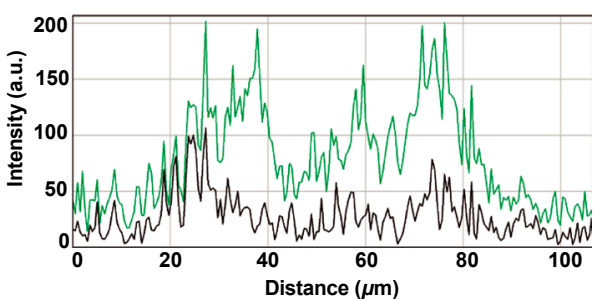

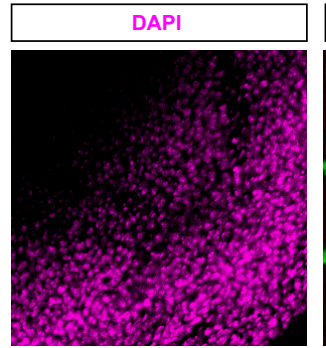
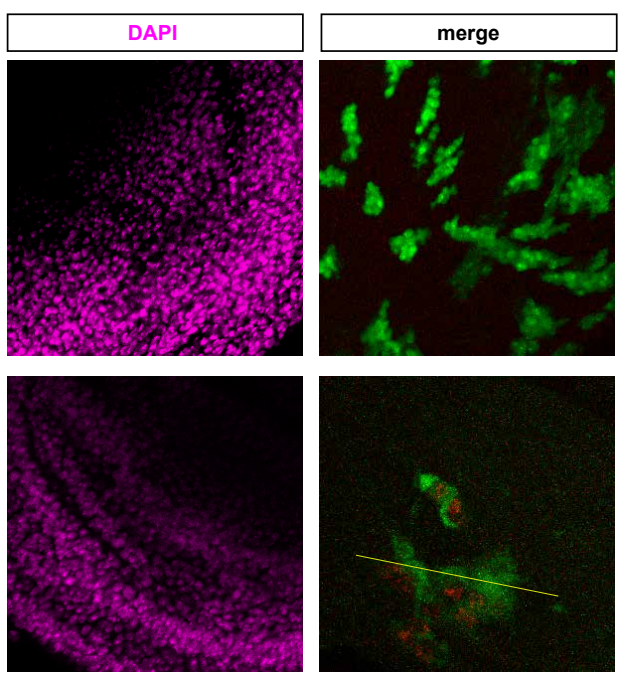

C

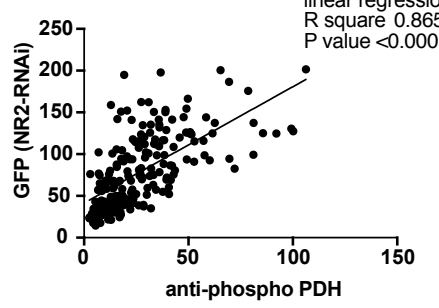

D Mitochondria size / MitoTracker Red

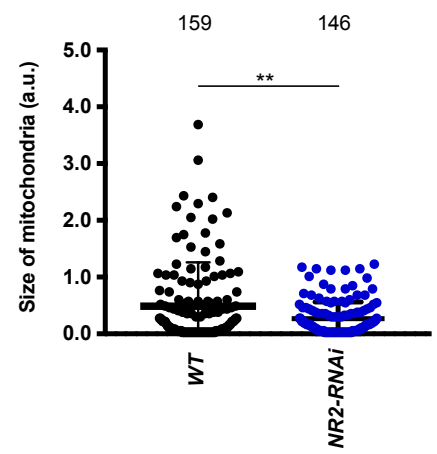

E

Losers among winners - Caspase activation
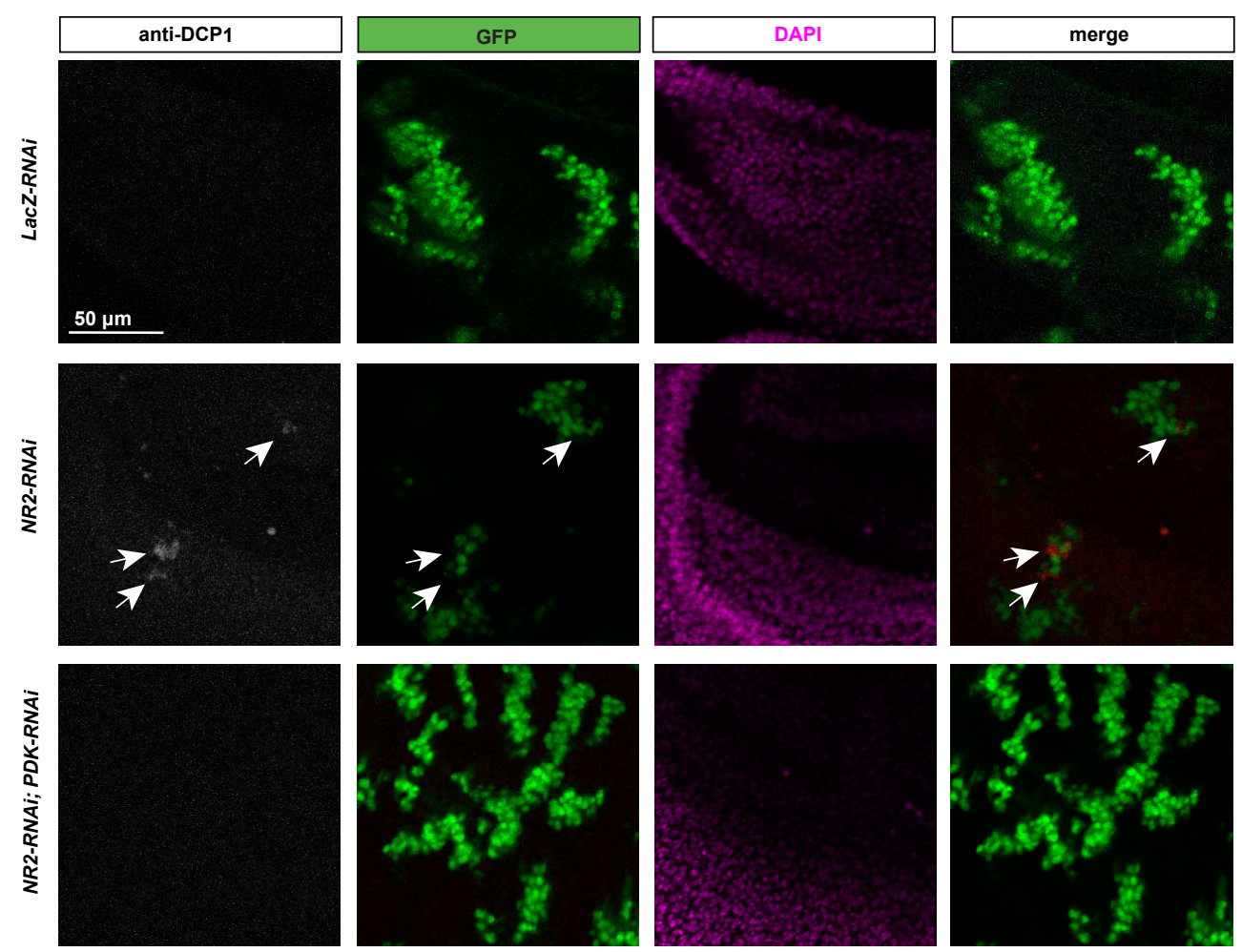

Figure S4.

Banreti and Meier, 2019 
bioRxiv preprint doi: https://doi.org/10.1101/2020.02 11.943498; this version posted February 12, 2020. The copyright holder for this preprint (which was not certified by peer review) is the author/funder. All rights reserved. No reuse allowed without permission.

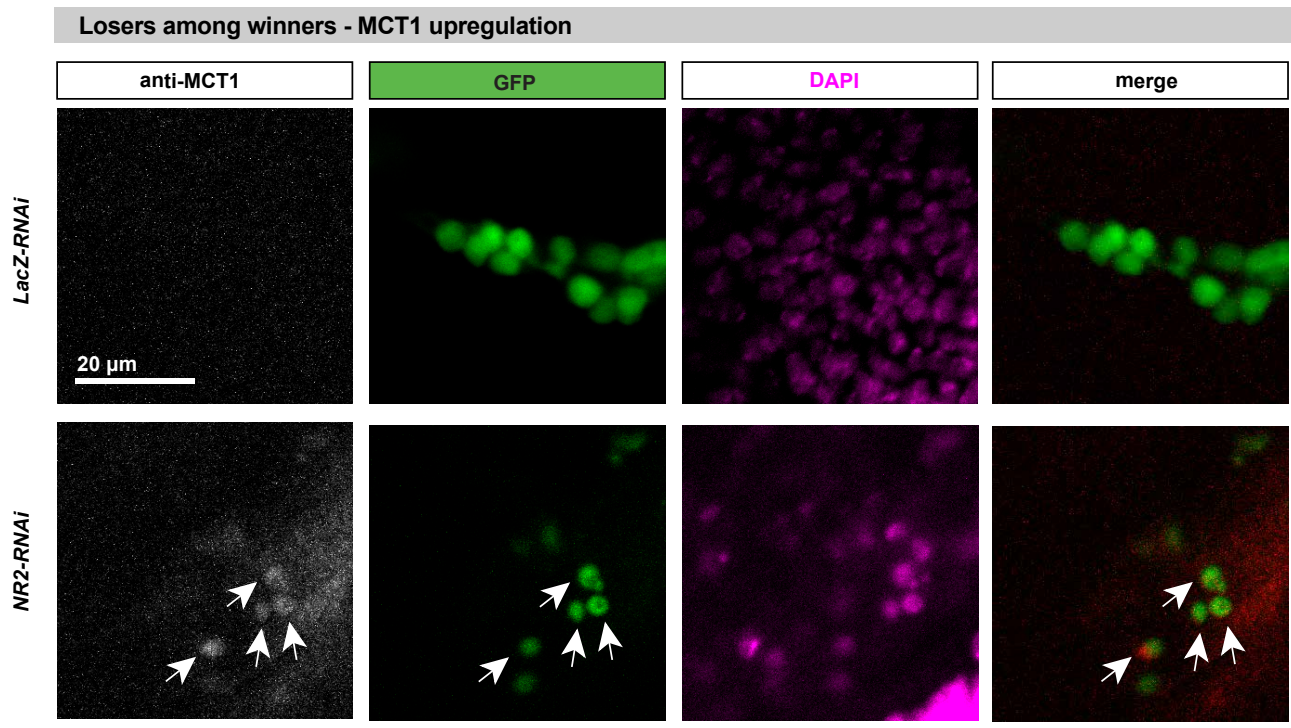

Figure S5.

Banreti and Meier, 2019 
WT cells among Myc winners - PDH inactivation
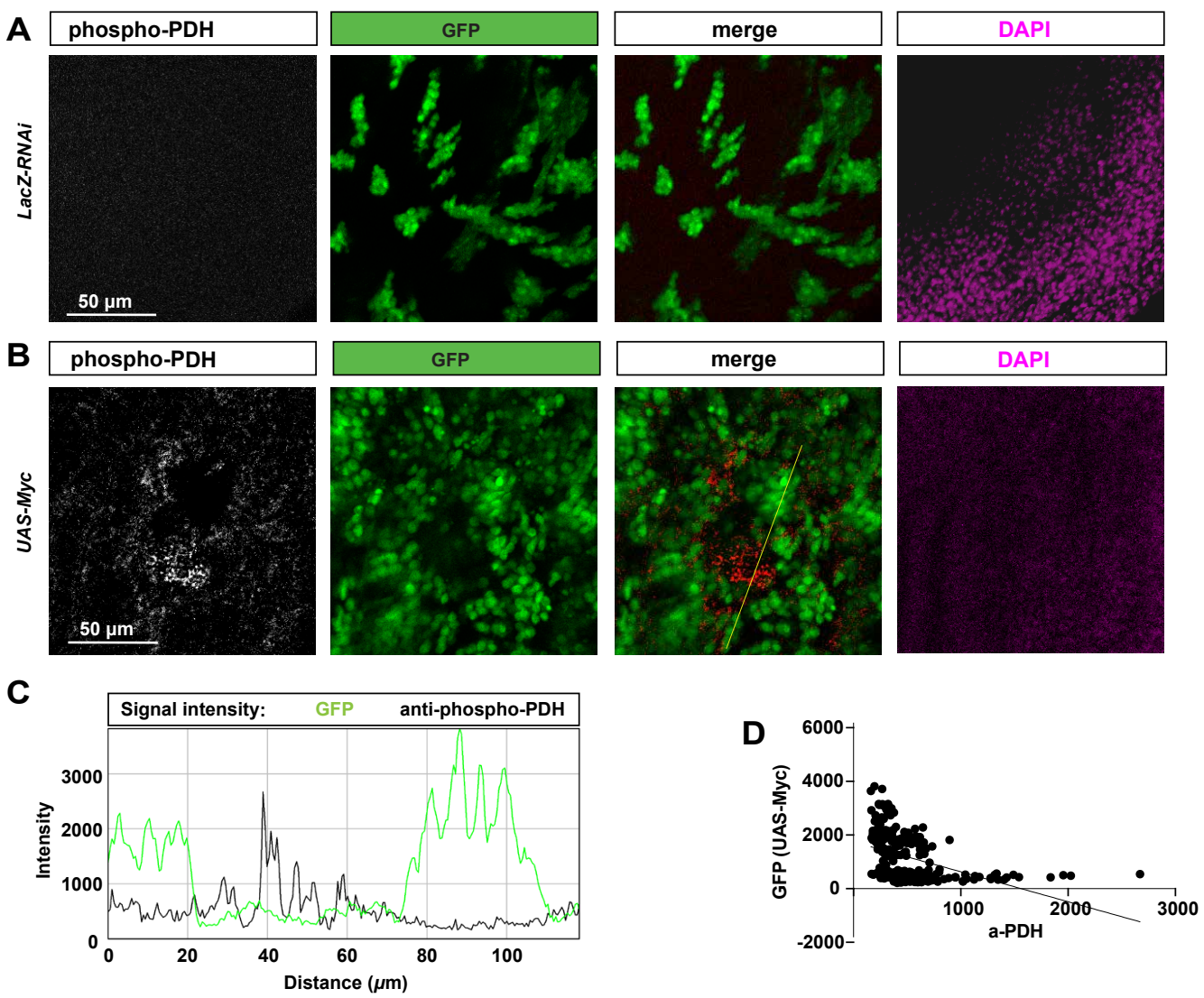

Figure S6.

Banreti and Meier, 2019 
bioRxiv preprint doi: https://doi.org/10.1101/2020.02.11.943498; this version posted February 12, 2020. The copyright holder for this preprint (which was not certified by peer review) is the author/funder. All rights reserved. No reuse allowed without permission.
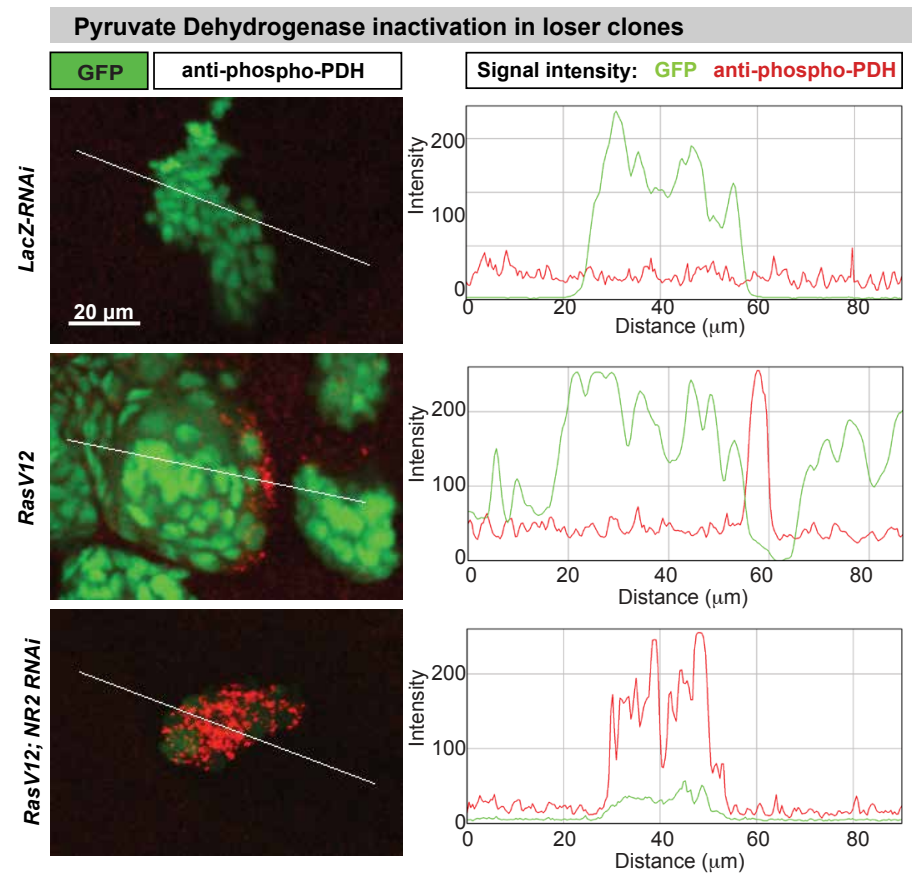

Figure S7.

Banreti and Meier, 2019 